\title{
Thermodynamic modeling of the $\mathrm{Ni}-\mathrm{H}$ system
}

\author{
Natacha Bourgeois, ${ }^{\dagger}$ Jean-Claude Crivello, ${ }^{\dagger}$ Arkapol Saengdeejing,, Ying Chen $^{\ddagger}$ \\ Pierre Cenedese, ${ }^{\dagger}$ and Jean-Marc Joubert*, $\dagger$ \\ Université Paris Est, ICMPE (UMR 7182), CNRS, UPEC, F-94320 Thiais, France, and \\ 6-6-11, Aramakiaza Aoba, Aoba-ku, Sendai, Miyagi 980-8579, Japan \\ E-mail: joubert@icmpe.cnrs.fr
}

\begin{abstract}
A new thermodynamic assessment of the $\mathrm{Ni}-\mathrm{H}$ system has been carried out. It takes into account the hydride formation and the presence of the miscibility gap. A complete literature study was reviewed in order to include high pressure data for the assessment. In addition to experimental data, first principles calculations were realized and used. The fcc solid solution of hydrogen in nickel was studied in the frame of the Cluster Expansion Method. Furthermore, a high pressure model was used to take into account the condensed phase compressibility at high pressure. Quasi-harmonic phonon calculations results were used to optimize the parameters related to this model.
\end{abstract}

\section{Introduction}

Hydrogen production and storage are considered as promising technologies to soften the fluctuations on the electric network induced by sustainable energy forms, whose intermittency

\footnotetext{
${ }^{*}$ To whom correspondence should be addressed

${ }^{\dagger}$ Université Paris Est, ICMPE (UMR 7182), CNRS, UPEC, F-94320 Thiais, France

${ }^{\ddagger}$-6-11, Aramakiaza Aoba, Aoba-ku, Sendai, Miyagi 980-8579, Japan
} 
still prevents large-scale development. The natural ability of several transition metals to absorb hydrogen reversibly represents an attractive and secure way to store hydrogen and use it as an energy carrier. To assess the individual storage properties of metals and to be able to predict the properties of multicomponent alloys, thermodynamic databases constructed in the frame of the Calphad approach (CALculation of PHAse Diagrams) can be used. ${ }^{1}$

Nickel is involved in many promising hydrogen storage alloys, combined with magnesium $\left(\mathrm{Mg}_{2} \mathrm{NiH}_{4}\right)$, lanthanum (Haucke phase $\left.\mathrm{LaNi}_{5}\right)$ or vanadium (V-Ni solid solutions). Therefore, an accurate thermodynamic description of the $\mathrm{Ni}-\mathrm{H}$ system is required. This system is characterized by the existence of a hydride $\mathrm{NiH}$ formed at very high pressure (above $5 \times 10^{8} \mathrm{~Pa}$ ). This hydride has the $\mathrm{NaCl}$ structure corresponding to the $\mathrm{Ni}$ fcc structure in which all the octahedral interstitial sites are occupied by hydrogen. The solubility of $\mathrm{H}$ in pure $\mathrm{Ni}$ is very low and the formation of the hydride occurs across a wide miscibility gap. The only Calphad assessment of this system by Zeng et al. ${ }^{2}$ did not take into account its formation and was limited to the description of the solution of $\mathrm{H}$ in fcc $\mathrm{Ni}$ at low concentration. The present assessment extends the description to higher pressures and considers the hydride formation. In this purpose, new experimental and calculated data were used. Calculations in the frame of the Density Functional Theory $(\mathrm{DFT})^{3}$ were performed to determine the energy of formation of the hydride $\mathrm{NiH}$. The enthalpies of mixing of $\mathrm{Ni}-\mathrm{H}$ solid solution were investigated with the Cluster Expansion Method $(\mathrm{CEM})^{4}$ based on DFT calculations. The model of Lu et al. ${ }^{5}$ was used in order to take into account the Gibbs energy contribution associated with the compressibility of both liquid and solid phases at high pressure. The specific parameters of this model were refined with the contribution of phonon calculations of $\mathrm{Ni}$ and $\mathrm{NiH}$ in the quasi-harmonic approximation (QHA). 


\section{Methodology}

\subsection{DFT calculations}

The DFT method was implemented using the Vienna Ab-initio Simulation Package (VASP). ${ }^{6,7}$ The generalized gradient approximation (GGA) was used for the exchange and correlation energy functional with the Perdew-Burke-Ernzerhof functional (PBE). ${ }^{8,9}$ Calculations were carried out with spin polarization. A high energy cutoff of $800 \mathrm{eV}$ was used for the plane wave basis set and a dense grid of k-points in the irreducible wedge of the Brillouin zone was generated with the Monkhorst-Pack scheme. ${ }^{10}$ The pseudopotential used included the Ni p-electrons.

The heat of formation of the hydride at $0 \mathrm{~K}$ was calculated from the total energies of $\mathrm{H}_{2}$ molecule, pure $\mathrm{Ni}$ and $\mathrm{NiH}$ in the $\mathrm{NaCl}$ structure, according to equation 1 . The formation energy was corrected with the zero-point energy (ZPE) contribution. This energy is associated with the fluctuations of atoms positions at $0 \mathrm{~K}$ and was determined with phonon calculations $^{11}$ in the harmonic approximation (HA).

$$
\triangle H_{\mathrm{NiH}}^{\mathrm{for}}=E_{\mathrm{NiH}}^{\mathrm{tot}}-E_{\mathrm{Ni}}^{\mathrm{tot}}-\frac{1}{2} E_{\mathrm{H}_{2}}^{\mathrm{tot}}
$$

\subsection{CEM calculations}

A CEM study was carried out using ATAT $^{12}$ code coupled with VASP calculations. This approach is based on the expression of the internal energy as a function of independent configurational functions $\{\xi\}_{\alpha}$, each of them related with a specific atomic cluster $\alpha$ (pairs, triplets,... ). In this frame, each lattice site $i$ is associated with an occupation variable $\sigma_{i}$ whose value characterizes the type of atom occupying the site $(+1$ or -1 in Ising Model). 
The total energy is represented as a polynomial function of the configurational variables:

$$
\begin{aligned}
E(\alpha) & =\sum_{\alpha} \nu_{\alpha} \xi_{\alpha} \\
\xi_{\alpha} & =<\sigma_{i_{1}} \sigma_{i_{2}} \ldots \sigma_{i_{N_{\alpha}}}>
\end{aligned}
$$

where the correlation function $\xi_{\alpha}$ associated with the cluster $\alpha$ of $N_{\alpha}$ sites, is the average of the occupation variables $\{\sigma\}_{i}$ over all the sites of the cluster. The variables $\nu_{\alpha}$ called effective cluster interactions (ECI) represent the energetic contribution of each cluster $\alpha$, including their multiplicity. They represent the parameter to be optimized. In the present study they have been refined on the basis of a set of DFT calculated energies of relevant ordered configurations. ${ }^{13}$ The correlation functions of the ordered structures being known, the ECI can be determined by inverting the matrix of the correlation functions in order to obtain a linear equation system whose unknown parameters are the ECI. They can be determined by fitting the calculated energies. On the basis of an ECI set, structures of low energy can be predicted, whose energies allow to refine the initial ECI values. Thus, iteratively, the lowest energy curve can be constructed, linking the most stable structures for each composition and representing the mixing energy at $0 \mathrm{~K}$ of the solid solution. This energy was determined in the present work for the solid solution of $\mathrm{H}$ occupying the octahedral sites of the Ni fcc parent lattice.

\subsection{Phonon calculations}

HA-phonon calculations within the supercell approach were performed to determine the ZPE correction of pure nickel and nickel hydride. First, DFT calculations were used in order to fully relax the lattice parameter of both $\mathrm{Ni}$ and $\mathrm{NiH}$ and reduce the residual inter-atomic forces under $10^{-8} \mathrm{eV} \cdot \AA^{-1} \cdot 2 \times 2 \times 2$ supercells with relevant atomic displacements were then built (Phonopy code ${ }^{11}$ ) and the sets of resulting inter-atomic forces were determined (VASP). Finally, the Phonopy code was used to determine from the set of forces, the frequencies of 
the eigenmodes of vibration. In the frame of the QHA, this above procedure was repeated for several cell volumes in order to include the pressure dependence of the eigenmodes. QHAphonon calculations were carried out to calculate the temperature dependence of the volume, the thermal expansion coefficient and the bulk modulus of $\mathrm{Ni}$ and $\mathrm{NiH}$.

\subsection{The Calphad method}

The semi-empirical Calphad method is based on the description of the Gibbs energy of each phase by equations with adjustable parameters. These parameters are refined by a least squares method to fit experimental or theoretical data and thus reproduce correctly the thermodynamic behavior of the system. One may find methodology description given in some reviews. ${ }^{14,15}$ Details on the models are given in section 4 .

\section{Literature review and selection of data}

The list of experimental data present in the literature on the $\mathrm{Ni}-\mathrm{H}$ system is given in Table 1.

\subsection{Pure nickel high temperature and pressure data}

A consistent set of molar volume values of fcc nickel $V_{m}^{\mathrm{Ni} \text {,fcc }}$ as a function of temperature was collected up to $1670 \mathrm{~K}$ by dilatation method and X-ray diffraction. ${ }^{16-19}$ The thermal expansion coefficient was measured up to the melting point. ${ }^{17,20,21}$ The variation of $V_{m}^{\mathrm{Ni} \text {,fcc }}$ with pressure was studied by synchrotron X-ray diffraction up to $7.4 \times 10^{9} \mathrm{~Pa} .{ }^{22}$ The coefficient of isothermal compressibility was reported at room temperature ${ }^{23}\left(5.4 \times 10^{-12} \mathrm{~Pa}^{-1}\right)$. Liquid nickel molar volume $V_{m}^{\mathrm{Ni}, \mathrm{LIQ}}$ temperature dependence was measured ${ }^{24-35}$ up to $2419 \mathrm{~K}$. Nickel melting point variation with pressure was measured with diamond anvil cell experiments up to $6.3 \times 10^{10} \mathrm{~Pa} .{ }^{36-39}$ 


\section{$3.2 \quad$ Hydrogen solubility data}

From the large panel of hydrogen solubility data present in the literature, ${ }^{40-55}$ only a consistent set of isothermal and isobaric measurements was conserved for the optimization. It has been noted that the solubility at $873 \mathrm{~K}$ measured by Smittenberg ${ }^{47}$ was slightly higher than that measured by Armbruster ${ }^{54}$ for identical pressures. Only Sieverts ${ }^{40}$ measured the solubility in the liquid phase. Fukai et al. ${ }^{56,57}$ reported solubility measurements in the hydrogen rich fcc phase at high pressure.

\subsection{Pressure-composition isothermal curves}

The nickel hydride can be synthesized using two methods: electrochemically ${ }^{58-62}$ or by applying very high hydrogen pressure. ${ }^{63-65}$ Absorption and desorption pressure-composition isotherms were measured ${ }^{62,66-68}$ from ambient temperature to $651 \mathrm{~K}$, showing an important hysteresis. Indeed, the average formation/decomposition plateau pressures of $\mathrm{NiH}$ at ambient temperature are respectively $6.23 \times 10^{8} \mathrm{~Pa}$ and $3.40 \times 10^{8} \mathrm{~Pa}$. Antonov et al. ${ }^{69}$ measured the plateau pressure on a temperature range from 375 to $651 \mathrm{~K}$.

\subsection{Other phase diagram data}

Serdyuk et al. ${ }^{70}$ reported the temperature and $\mathrm{H}$ concentration of the solid-liquid-gas equilibrium under hydrogen pressure at $10^{8} \mathrm{~Pa}$. Shapovalov and Serdyuk ${ }^{41}$ measured the temperature of this 3 -phase equilibrium up to $5.5 \times 10^{7} \mathrm{~Pa}$ as a function of hydrogen pressure, highlighting its decrease during the absorption process. Fukai et al. ${ }^{70}$ confirmed this trend with measurements at higher hydrogen pressure $\left(2.4\right.$ to $\left.6.2 \times 10^{7} \mathrm{~Pa}\right)$.

In addition, the Curie point decrease with increasing hydrogen pressure ${ }^{69}$ was reported up to $284 \mathrm{~K}$ at $1.26 \times 10^{9} \mathrm{~Pa}$. The compositions on both sides of the miscibility gap were measured by Antonov et al. ${ }^{69}$ and Fukai et al. ${ }^{56}$ 


\subsection{Thermodynamic data}

Despite the difficulties to carry out calorimetric measurements at high pressure, three papers report the molar enthalpy of hydride formation and/or decomposition. Tkacz and Baranowski ${ }^{67}$ found $\Delta H=-5.0 \mathrm{~kJ} / \mathrm{mol}-\mathrm{H}$ at $6.2 \times 10^{8} \mathrm{~Pa}$ and $\Delta H=-3.1 \mathrm{~kJ} / \mathrm{mol}-\mathrm{H}$ at $3.4 \times 10^{8} \mathrm{~Pa}$ during the formation and decomposition respectively. Including the contribution of the gas compressibility, the calculated enthalpies at normal pressure are $-8.1 \mathrm{~kJ} / \mathrm{mol}-\mathrm{H}$ (formation) and $-4.5 \mathrm{~kJ} / \mathrm{mol}-\mathrm{H}$ (decomposition). Baranowski and Czarnota ${ }^{71}$ report a molar enthalpy measured at ambient temperature and pressure during the decomposition with a differential calorimeter $(-5.0 \mathrm{~kJ} / \mathrm{mol}-\mathrm{H})$, consistent with the corrected enthalpy of Tkacz and Baranowski of $-4.5 \mathrm{~kJ} / \mathrm{mol}-\mathrm{H}$. Besides, Czarnota and Baranowski ${ }^{72}$ realized a set of calorimetric measurements during the spontaneous decomposition at normal pressure of several samples prepared at different concentrations, from 0.02 to 0.36 hydrogen molar fraction $x(H)$. The trend $(\Delta H=-4.2 \mathrm{~kJ} / \mathrm{mol}-\mathrm{H}$ at $x(H)=0.36)$ is in agreement with the other

experimental values. Furthermore, the partial enthalpy values derived from the plateau pressures of Antonov ${ }^{69}$ are $-5.1 \mathrm{~kJ} / \mathrm{mol}-\mathrm{H}$ (formation) and $-8.2 \mathrm{~kJ} / \mathrm{mol}-\mathrm{H}$ (decomposition). 
Table 1: Compilation of experimental data.

\begin{tabular}{lcl} 
Conditions & Refs. & used \\
\hline \multicolumn{1}{c}{ Temperature dependence of fcc nickel molar volume. } \\
$T=493$ to $1671 \mathrm{~K}$ & 16 & only for compar- \\
$T=500$ to $788 \mathrm{~K}$ & 17 & ison (comp.) \\
$T=298 \mathrm{~K}$ & 18 & comp. \\
$T=89$ to $297 \mathrm{~K}$ & 19 & comp.
\end{tabular}

Temperature dependence of nickel thermal expansion coefficient.

$\begin{array}{lcc}T=381 \text { to } 1102 \mathrm{~K} & 17 & \text { comp. } \\ T=292 \text { to } 1499 \mathrm{~K} & 20 & \text { comp. } \\ T=2.8 \text { to } 1729 \mathrm{~K} & 21 & \text { comp. }\end{array}$

Nickel molar volume pressure dependence.

$P=1 \times 10^{5}$ to $7.4 \times 10^{9} \mathrm{~Pa} \quad 22 \quad$ comp.

Nickel isothermal compressibility.

$T=298 \mathrm{~K} \quad 23 \quad$ comp.

Temperature dependence of the liquid nickel density.

$T=1726$ to $2151 \mathrm{~K}$

$\begin{array}{ll}24 & \text { yes } \\ 25 & \text { yes } \\ 26 & \text { yes } \\ 27 & \text { yes } \\ 28 & \text { yes } \\ 29 & \text { yes } \\ 30 & \text { yes } \\ 31 & \text { yes }\end{array}$




\begin{tabular}{|c|c|c|c|}
\hline Conditions & Refs. & used & \\
\hline Melt. point & 32 & yes & \\
\hline$T=1773 \mathrm{~K}$ & 33 & yes & \\
\hline$T=1823 \mathrm{~K}$ & 34 & $\begin{array}{l}\text { no } \\
\text { cies) }\end{array}$ & (discrepan- \\
\hline Melt. point & 35 & $\begin{array}{l}\text { no } \\
\text { cies) }\end{array}$ & (discrepan- \\
\hline$T=1730$ to $1974 \mathrm{~K}$ & 73 & $\begin{array}{l}\text { no } \\
\text { cies) }\end{array}$ & (discrepan- \\
\hline
\end{tabular}

fcc nickel melting point pressure dependence.

$\begin{array}{lll}P=1.0 \times 10^{8} \text { to } 6.3 \times 10^{10} \mathrm{~Pa} & 36 & \text { no (higher than } \\ P=1.0 \times 10^{5} \text { to } 5.8 \times 10^{10} \mathrm{~Pa} & 37 & \text { the other data) } \\ P=1.0 \times 10^{5} \text { to } 5.4 \times 10^{10} \mathrm{~Pa} & 38 & \text { yes } \\ P=8.7 \times 10^{9} \text { to } 5.1 \times 10^{10} \mathrm{~Pa} & 39 & \text { yes }\end{array}$

Isobaric hydrogen solubility data.

$\begin{array}{lll}P=1.013 \times 10^{5} \mathrm{~Pa}-T=485 \text { to } 1873 \mathrm{~K} & 40 & \text { yes } \\ P=1.013 \times 10^{7} \mathrm{~Pa}-T=818 \text { to } 1636 \mathrm{~K} & 41 & \text { yes } \\ P=1.000 \times 10^{5} \mathrm{~Pa}-T=779 \text { to } 1650 \mathrm{~K} & 42 & \text { comp. } \\ P=1.010 \times 10^{5} \mathrm{~Pa}-T=623 \text { to } 1495 \mathrm{~K} & 43 & \text { comp. } \\ P=1.013 \times 10^{5} \mathrm{~Pa}-T=357 \text { to } 554 \mathrm{~K} & 44 & \text { yes } \\ P=1.013 \times 10^{5} \mathrm{~Pa}-T=999 \text { to } 1516 \mathrm{~K} & 74 & \text { comp. } \\ P=1.013 \times 10^{5} \mathrm{~Pa}-T=723 \text { to } 1223 \mathrm{~K} & 45 & \text { comp. } \\ P=1.013 \times 10^{5} \mathrm{~Pa}-T=579 \text { to } 1479 \mathrm{~K} & 46 & \text { comp. } \\ P=1.333 \times 10^{1} \mathrm{~Pa}-T=873 \text { to } 573 \mathrm{~K} & 47 & \text { comp. } \\ P=1.013 \times 10^{5} \mathrm{~Pa}-T=1007 \text { to } 1494 \mathrm{~K} & 48 & \text { no }\end{array}$




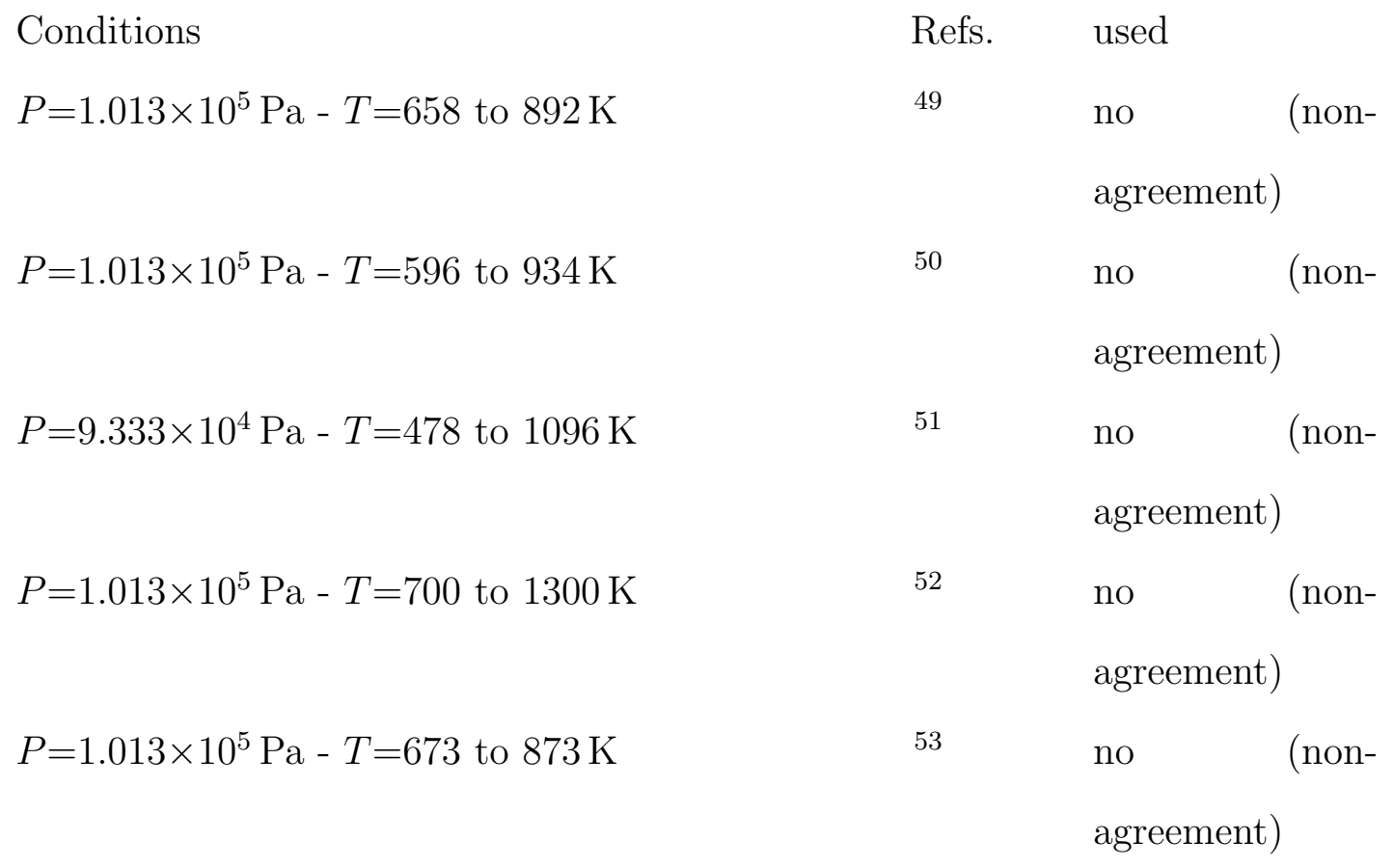

Isothermic hydrogen solubility data.

$\begin{array}{lll}P=6.00 \times 10^{-1} \text { to } 2.35 \times 10^{1} \mathrm{~Pa}-T=573-873 \mathrm{~K} & 47 & \text { yes } \\ P=1.01 \times 10^{-1} \text { to } 2.40 \times 10^{2} \mathrm{~Pa}-T=673-773-873 \mathrm{~K} & 54 & \text { yes } \\ P=1.21 \times 10^{4} \text { to } 1.24 \times 10^{5} \mathrm{~Pa}-T=1073 \mathrm{~K} & 55 & \text { no } \\ P=2.50 \times 10^{6} \text { to } 9.37 \times 10^{7} \mathrm{~Pa}-T=873-1073-1473- & 42 & \text { comp. } \\ 1623 \mathrm{~K} & & \\ P=2.56 \times 10^{6} \text { to } 6.29 \times 10^{7} \mathrm{~Pa}-T=873-1073-1473- & 41 & \text { yes except the } \\ 1623 \mathrm{~K} & & \text { data at } 873 \mathrm{~K}\end{array}$

Hydrogen solubility data in the hydrogen rich phase.

$P=1.1 \times 10^{9} \mathrm{~Pa}$ to $P=5.4 \times 10^{9} \mathrm{~Pa}-T=293$ to ${ }^{56} \quad$ comp. (non$1062 \mathrm{~K} \quad$ defined temperature and pressure) 


\begin{tabular}{|c|c|c|}
\hline Conditions & Refs. & used \\
\hline \multicolumn{3}{|c|}{ Pressure-composition isothermal curves. } \\
\hline$T=298 \mathrm{~K}$ & 62 & comp. \\
\hline$T=298 \mathrm{~K}$ & 63 & comp. \\
\hline$T=298 \mathrm{~K}$ & 65 & comp. \\
\hline$T=298-338 \mathrm{~K}$ & 64 & comp. \\
\hline \multicolumn{3}{|c|}{ Decomposition plateau pressure. } \\
\hline$T=298 \mathrm{~K}$ & 63 & comp. \\
\hline$T=298-340 \mathrm{~K}$ & 66 & comp. \\
\hline$T=298-338 \mathrm{~K}$ & 64 & comp. \\
\hline$T=298 \mathrm{~K}$ & 65 & comp. \\
\hline$T=298 \mathrm{~K}$ & 62 & comp. \\
\hline$T=298 \mathrm{~K}$ & 67 & comp. \\
\hline$T=298 \mathrm{~K}$ & 68 & comp. \\
\hline \multicolumn{3}{|c|}{ Formation plateau pressure. } \\
\hline$T=298-340 \mathrm{~K}$ & 66 & comp. \\
\hline$T=298-338 \mathrm{~K}$ & 64 & yes \\
\hline$T=298 \mathrm{~K}$ & 65 & comp. \\
\hline$T=298 \mathrm{~K}$ & 67 & comp. \\
\hline$T=375$ to $651 \mathrm{~K}$ & 69 & yes \\
\hline$T=298 \mathrm{~K}$ & 75 & no (non- \\
\hline & & agreement) \\
\hline
\end{tabular}

Melting point of nickel under hydrogen pressure.
$P=1.00 \times 10^{5}$ to $5.47 \times 10^{7} \mathrm{~Pa}$
$41 \quad$ comp.
$P=2.45 \times 10^{9}$ to $6.18 \times 10^{9} \mathrm{~Pa}$
$56 \quad$ comp.
$P=1.00 \times 10^{8} \mathrm{~Pa}$
$70 \quad$ yes 


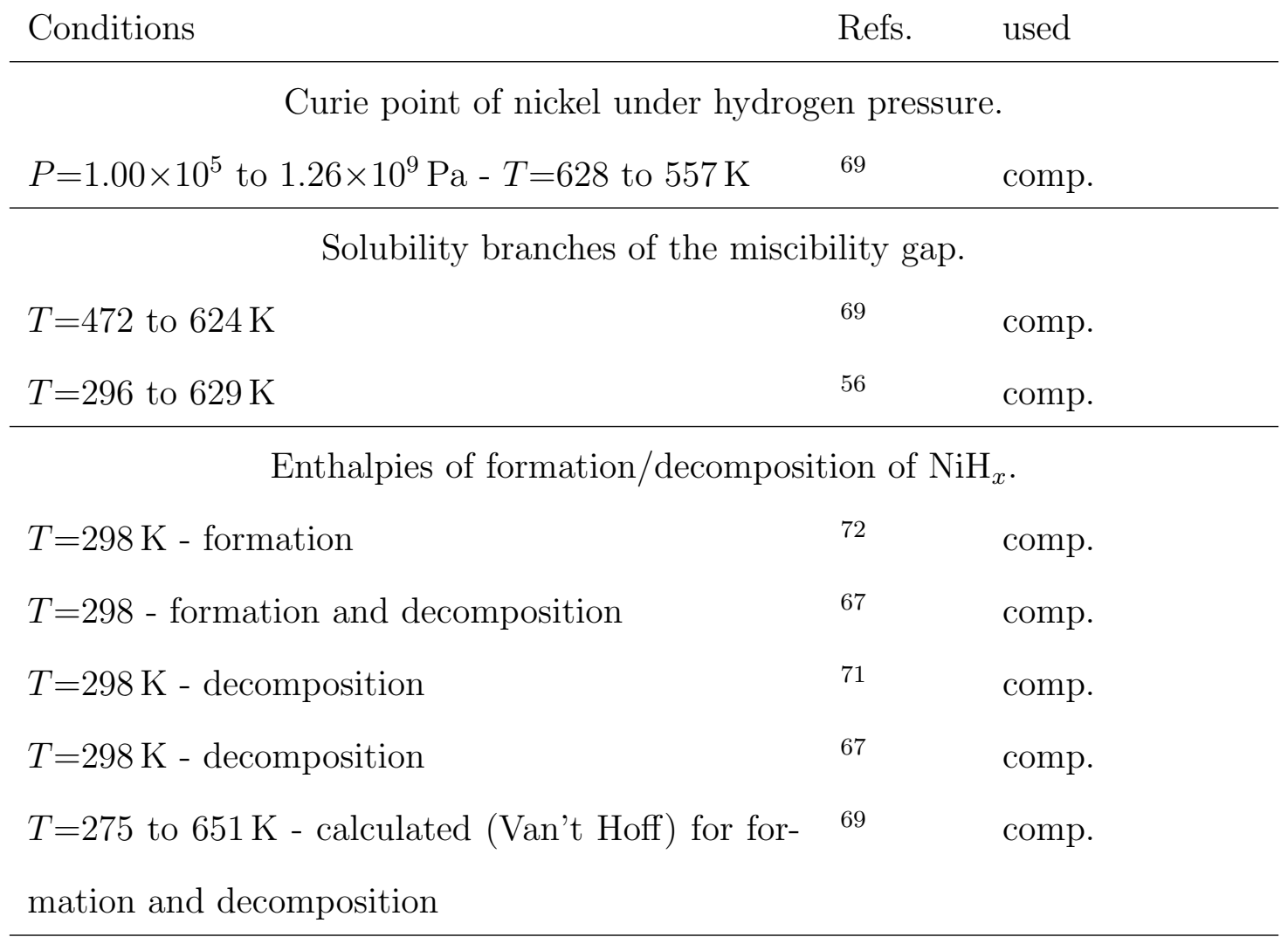

\section{Thermodynamic modeling}

\subsection{Gas phase}

The gas phase is composed of the species $\mathrm{H}_{2}$ and Ni. The standard Gibbs energy of gaseous dihydrogen and nickel at $P_{0}=10^{5} \mathrm{~Pa}$ were taken from the PURE database ${ }^{76}$ and SSUB3 database, ${ }^{77}$ respectively.

The non ideal behavior of hydrogen gas at high pressure was taken into account using the equation of state for hydrogen gas developed by Joubert. ${ }^{78}$ Concerning gaseous nickel, a simple model was adopted, assuming that the asymptotic limit of the molar volume at high pressure is equal to that of solid nickel. Besides, we assumed that there is no interaction between dihydrogen molecules and nickel. 


\subsection{Solid and liquid phases}

The interstitial solid solution was described with a two-sublattice model in agreement with the nickel hydride fcc crystal structure:

- the first sublattice corresponds to the fcc host lattice, fully occupied by nickel atoms

- the second sublattice corresponds to the octahedral interstitial sites, occupied by vacancies and hydrogen.

The solid phase was therefore described in the Compound Energy Formalism $(\mathrm{CEF})^{79}$ by: $(\mathrm{Ni})_{1}:(\mathrm{Va}, \mathrm{H})_{1}$.

In the model of Zeng et al., ${ }^{2}$ the liquid phase was described using a substitutional solution model. The Gibbs energy of the hypothetical end member hydrogen liquid was fixed to a constant value, refined with experimental data from $\mathrm{Ni}-\mathrm{H}$ and $\mathrm{Mg}-\mathrm{H}$ systems. This value was found incompatible with the present model, in particular at high pressure. Consequently, it was decided to describe the liquid with an interstitial sublattice model, identical to the solid phase description. The validity of this model relies on the hypothesis that hydrogen concentration in the liquid is far from reaching one hydrogen per nickel atom. This assumption is justified by the very low solubility of $\mathrm{H}$ measured in liquid ${ }^{40}\left(2.2 \times 10^{-3}\right.$ hydrogen molar fraction at $1873 \mathrm{~K}$ and $1.0 \times 10^{5} \mathrm{~Pa}$ ), almost 250 times lower than the limit allowed by the model.

The advantage of this model compared to the substitutional one is to avoid the definition of metallic $\mathrm{H}$ in the liquid state with no reasonable physical meaning but which should be identical for any $M-\mathrm{H}$ system. Instead, the defined metastable end-member $\mathrm{NiH}$ has an impact only in $\mathrm{Ni}-\mathrm{H}$ system. The present description is thus made compatible with other Calphad models of $M-\mathrm{H}$ systems.

The Gibbs energy of the phase $\varphi$ ( $\varphi=$ fcc, liquid) is given by:

$$
G^{\varphi}={ }^{\mathrm{ref}} G^{\varphi}+{ }^{\mathrm{id}} G^{\varphi}+{ }^{\mathrm{ex}} G^{\varphi}+{ }^{\mathrm{phys}} G^{\varphi}
$$


with

- ${ }^{\text {ref }} G^{\varphi}$ : reference Gibbs energy

- ${ }^{\text {id }} G^{\varphi}$ : ideal Gibbs energy

- ${ }^{\text {ex }} G^{\varphi}$ : excess Gibbs energy

- ${ }^{\text {phys }} G^{\varphi}$ : physical Gibbs energy.

\subsubsection{Reference Gibbs energy}

The reference Gibbs energy can be written as:

$$
{ }^{\mathrm{ref}} G^{\varphi}=y_{\mathrm{VA}} G_{\mathrm{Ni}}^{\varphi}+y_{\mathrm{H}} G_{\mathrm{Ni}: \mathrm{H}}^{\varphi}
$$

$G_{\mathrm{Ni}}^{\varphi}$ were taken from the PURE database. $G_{\mathrm{Ni}: \mathrm{H}}^{\varphi}$ are described by the following equations.

$$
\begin{aligned}
& G_{\mathrm{Ni}: \mathrm{H}}^{\mathrm{fcc}}=G_{\mathrm{Ni}}^{\mathrm{SER}}+\frac{1}{2} G_{\mathrm{H}_{2}}^{\mathrm{SER}}+V_{1}+V_{2} \cdot T+V_{3} \cdot T^{2} \\
& G_{\mathrm{Ni}: \mathrm{H}}^{\mathrm{LIQ}}=G_{\mathrm{Ni}}^{\mathrm{SER}}+\frac{1}{2} G_{\mathrm{H}_{2}}^{\mathrm{SER}}+V_{4}+V_{5} \cdot T
\end{aligned}
$$

with $V_{i}$ parameters to be optimized.

\subsubsection{Ideal Gibbs energy}

The ideal Gibbs energy results from the random mixing of $\mathrm{H}$ and vacancy on the second sublattice:

$$
{ }^{\mathrm{id}} G^{\varphi}=-T \cdot{ }^{\mathrm{conf}} S^{\varphi}=R T\left(y_{\mathrm{VA}} \ln y_{\mathrm{VA}}+y_{\mathrm{H}} \ln y_{\mathrm{H}}\right)
$$




\subsubsection{Excess Gibbs energy}

The excess Gibbs energy, representing the interaction between hydrogen and vacancies on the interstitial sites, is described with the Redlich-Kister model: ${ }^{80}$

$$
{ }^{\mathrm{ex}} G^{\varphi}=y_{\mathrm{H}} y_{\mathrm{VA}} \sum_{i=0}^{n} L_{\mathrm{H}, \mathrm{VA}}^{i, \varphi}\left(y_{\mathrm{H}}-y_{\mathrm{VA}}\right)^{i}
$$

$L_{\mathrm{H}, \mathrm{VA}}^{i, \varphi}$ can be made temperature dependent following:

$$
L_{\mathrm{H}, \mathrm{VA}}^{i, \varphi}=a^{i, \varphi}+b^{i, \varphi} \cdot T
$$

with $a^{i, \varphi}$ and $b^{i, \varphi}$ are the parameters to be optimized.

\subsubsection{Physical Gibbs energy}

Two contributions were added to the total Gibbs energy: the first one from magnetism ${ }^{\mathrm{mag}} G^{\mathrm{fcc}}$ and the second ${ }^{\mathrm{comp}} G^{\varphi}$ representing the pressure-dependent part of the Gibbs energy.

$$
\begin{aligned}
{ }^{\text {phys }} G^{\mathrm{fcc}} & ={ }^{\mathrm{mag}} G^{\mathrm{fcc}}+{ }^{\text {comp }} G^{\mathrm{fcc}} \\
{ }^{\text {phys }} G^{\mathrm{LIQ}} & ={ }^{\text {comp }} G^{\mathrm{LIQ}}
\end{aligned}
$$

Magnetic contribution The magnetic contribution is present only in the fcc phase and can be described by:

$$
{ }^{\mathrm{mag}} G^{\mathrm{fcc}}=R T f(\tau) \ln (\beta+1)
$$

where $f(\tau)$ is an empirical function proposed by Inden ${ }^{81}$ and adapted by Hillert and Jarl, ${ }^{82} \beta$ is the Bohr magneton number (composition dependent) and $\tau$ is $T / T_{C}$ with $T_{C}$ the Curie Temperature, composition and pressure dependent. 
Pressure-dependent contribution In the considered pressure range, a model where only the gas phase depends on pressure is no longer valid. Inconsistencies appear like an important destabilization of the gas at high pressure, leading to a dramatic increase of the boiling point of nickel. Furthermore, the condensed phases have non negligible compressibility and the work associated with the volume change under high pressure may not be neglected. The resulting contribution ${ }^{\text {comp }} \triangle G^{\varphi}$ has thus to be considered, expressed as:

$$
\text { comp } \triangle G^{\varphi}=\int_{P_{0}}^{P} V(T, P) d P
$$

In this frame, we used the model of Lu et al., ${ }^{5}$ implemented in Thermo-Calc. The temperature and pressure dependencies of the molar volume of both solid and liquid phases are described on the basis of an empirical linear relationship between molar volume and bulk modulus: ${ }^{83}$

$$
V_{m}(T, P)=x+y \ln \left(\frac{B}{P_{\text {ref }}}\right)
$$

with $x$ and $y$ functions of temperature, characteristic of the considered material.

After integration the Gibbs energy derived from this equation of state can be written as:

$$
{ }^{\text {comp }} \triangle G^{\varphi}=\frac{c(T)}{\kappa\left(T, P_{0}\right)}\left[\exp \left(\frac{V_{m}(T, P)-V_{m}\left(T, P_{0}\right)}{c(T)}\right)-1\right]
$$

with $c(T)$ the adjustable parameter.

For each end member, the four following parameters were assessed:

- $V_{0}\left[\mathrm{~m}^{3} \cdot \mathrm{mol}^{-1}\right]$ : molar volume of reference at $T_{0}=0 \mathrm{~K}, P=1 \mathrm{bar}$

- $V_{A}(T)$ [-]: integrated thermal expensivity $V_{A}(T)=\int_{T_{0}}^{T} 3 \alpha(T) d T$, driving the variation of the molar volume with temperature at constant pressure

- $V_{C}(T)\left[\mathrm{m}^{3} \cdot \mathrm{mol}^{-1}\right]:$ adjustable parameter $c(T)$ 
- $V_{K}(T)\left[\mathrm{Pa}^{-1}\right]$ : isothermal compressibility at 1 bar $\kappa\left(T, P_{0}\right)$ the inverse of bulk modulus, representing the volume variation with pressure.

\section{Results and discussion}

\subsection{DFT calculations}

The electronic structure of pure nickel corresponds to ferro-magnetic state with a magnetic moment $M=0.62 \mathrm{~A} \cdot \mathrm{m}^{2}$. Whereas in the hydride phase, the additional electron, given by the hydrogen atom, leads to the complete filling of the Ni-3d states. Thus, the hydride turns to a paramagnetic state (density of state not shown). No magnetic model was therefore considered in the Calphad description of this end member.

The following calculated enthalpy of formation was found: $E_{\mathrm{for}}^{\mathrm{NiH}}=-7.0 \mathrm{~kJ} / \mathrm{mol}-\mathrm{H}$. Taking into account the $\mathrm{ZPE}$ at $0 \mathrm{~K}$, the corrected value is $-7.8 \mathrm{~kJ} / \mathrm{mol}-\mathrm{H}$. As shown in Figure 1, the calculated value is not fully in agreement with the experiments. Since NiH is associated to a low heat of formation, its estimation is dominated by pure elements energy contributions whose calculation is not entirely satisfactory for $\mathrm{H}$ in our DFT description. Indeed, this inaccuracy is partly related to the inappropriate plane-wave basis set. Thus, low weight was associated to the DFT formation enthalpy value in the Calphad assessment. 


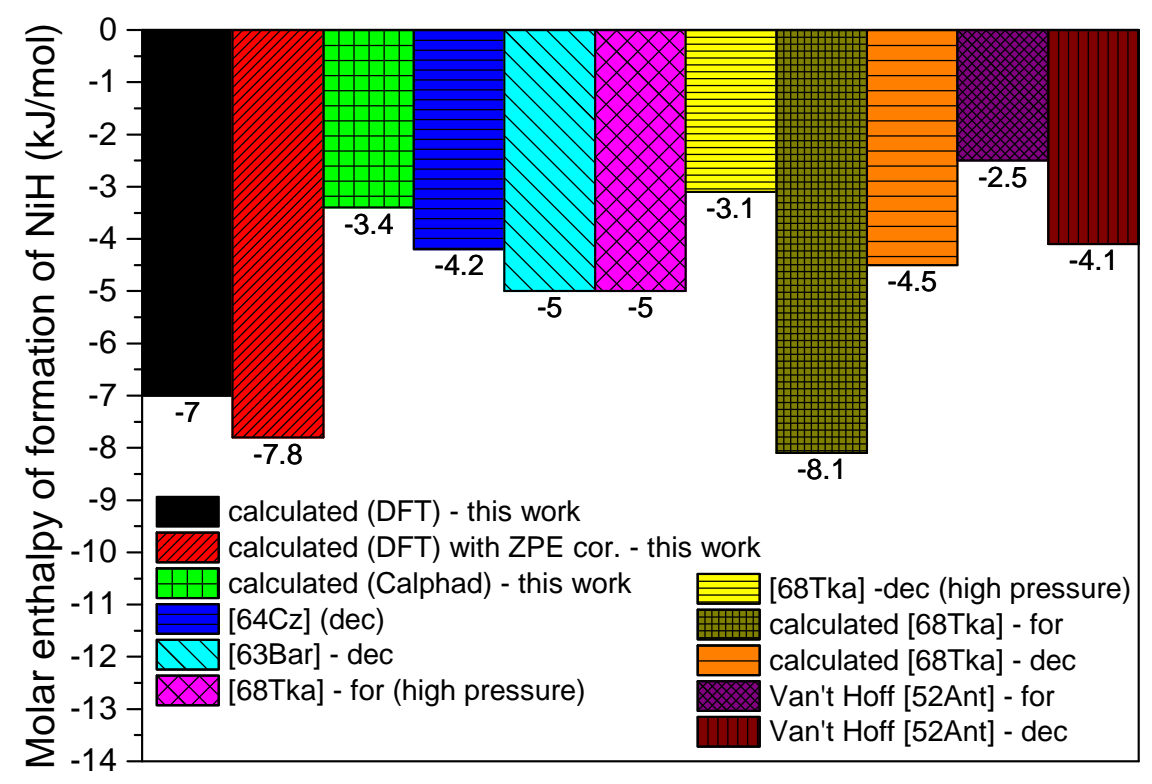

Figure 1: Calculated enthalpy of formation at $0 \mathrm{~K}$ - comparison with raw and derived experimental data obtained during the formation (for) or decomposition (dec) process.

Besides, Ni and $\mathrm{NiH}$ molar volume relation with mechanical pressure was investigated by calculating the external pressure on cells whose lattice parameters has been reduced. As shown in Figure 2, the data for $\mathrm{Ni}$ are in agreement with the experimental measurements ${ }^{22}$ in a pressure range up to $7.4 \times 10^{9} \mathrm{~Pa}$. The results were used to assess the parameters of the high pressure model of Lu et al. 


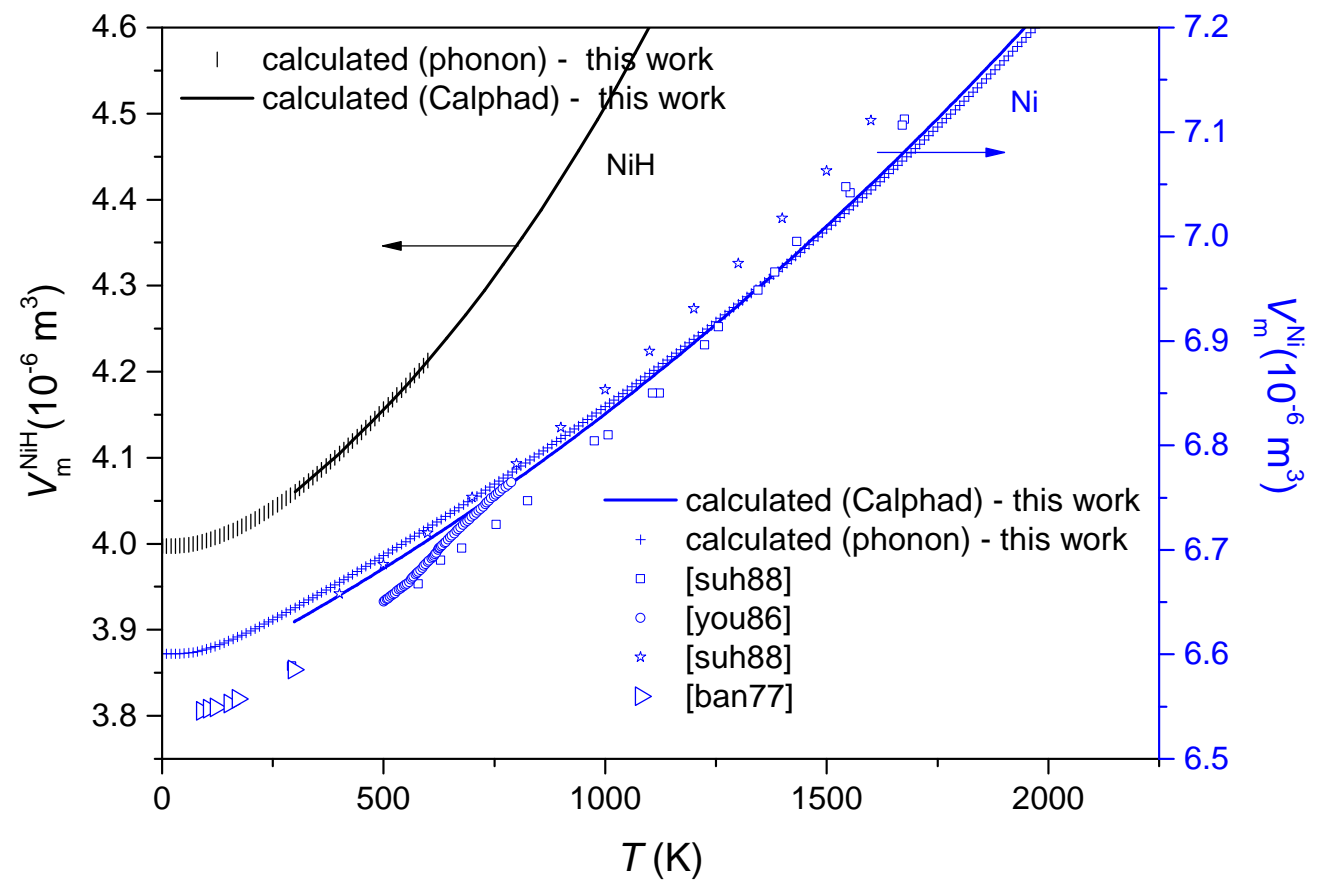

Figure 2: Molar volume of pure $\mathrm{Ni}$ as a function of pressure calculated by DFT at $0 \mathrm{~K}$ (filled squares) and by Calphad assessment at $298 \mathrm{~K}$ (open squares). Experimental values of Zhang et $a l .{ }^{22}$ at $298 \mathrm{~K}$.

\subsection{CEM calculations}

The calculated energies of mixing (squares) and the ones predicted by the model (crosses) are both represented in Figure 3 as a function of hydrogen site fraction $y(H)$. The energies of mixing are normalized with the total energies of the references $\mathrm{Ni}$ and $\mathrm{NiH}$. Presenting a cross validation score of $2.7 \times 10^{-31}$, the 21 calculated energies are satisfactorily reproduced by the model which considers the contributions up to clusters of four atoms.

The energies of mixing allow to quantify the interactions between $\mathrm{H}$ and vacancies on the interstitial sublattice. In the $\mathrm{Ni}-\mathrm{H}$ system, these interactions were found repulsive and

\footnotetext{
${ }^{1}$ The predictive power of the fit can be quantified by the cross-validation $(\mathrm{CV})$ score, ${ }^{12}$ defined as $(C V)^{2}=n^{-1} \sum_{i=1}^{n}\left(E_{i}-\hat{E}_{(i)}\right)^{2}$, where $n$ is the number of structures, $E_{i}$ the calculated energy of a structure $i$ and $\hat{E}_{(i)}$ the predicted energy for the structure $i$, obtained by a least-square fit realized on the set of structures without the $i$ th one.
} 
result in positive energies of mixing, highlighting the instability of the solid solution. Indeed, a miscibility gap is experimentally observed in the fcc phase. This phase separates into two phases with the same structure but different $\mathrm{H}$ concentrations.

In the Calphad method, the energies of mixing correspond to the excess Gibbs energy at $0 \mathrm{~K}$. The results were thus used in the present Calphad model to determine the excess enthalpy at $0 \mathrm{~K}$ of the $\mathrm{Ni}-\mathrm{H}$ solid solution. The good agreement between the CEM and Calphad models is highlighted in Figure 3.

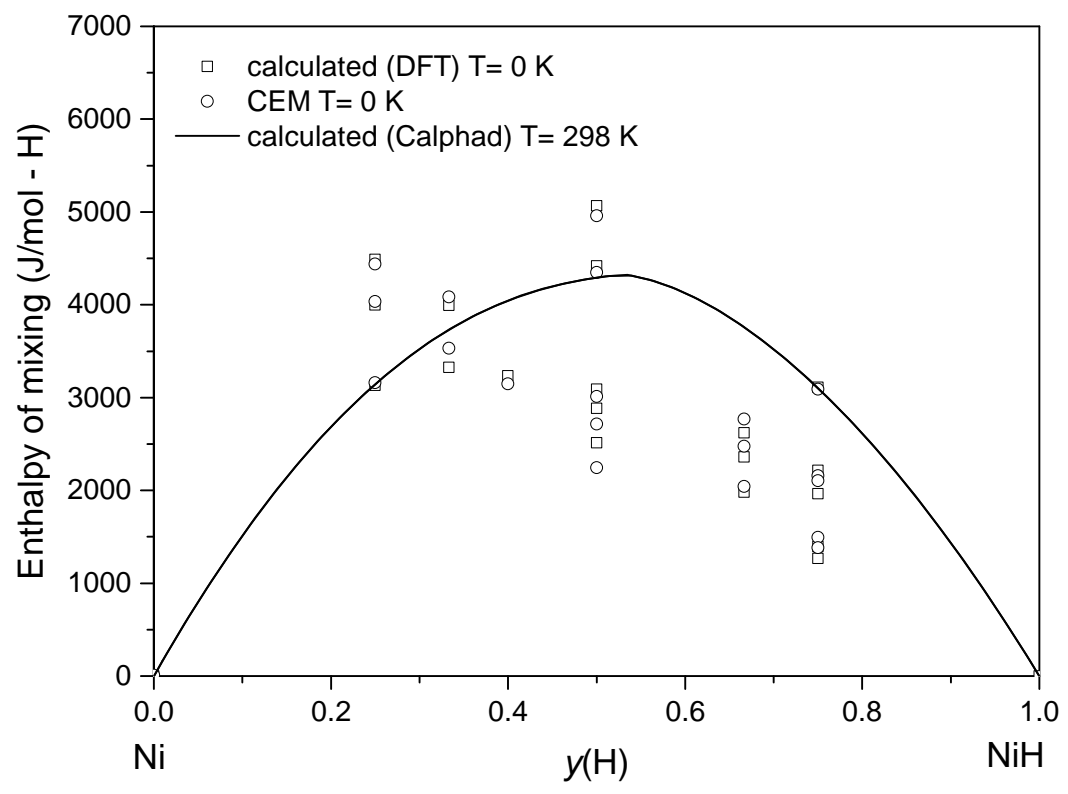

Figure 3: Calculated enthalpy of mixing (DFT) of the $\mathrm{Ni}-\mathrm{H}$ solid solution (squares) as a function of hydrogen site fraction $y(H)$ compared with the ones determined by the CEM model (circles). Calculated enthalpy of mixing (Calphad) at $298 \mathrm{~K}$.

\subsection{Phonon calculations}

Quasi-harmonic phonon calculations allowed to calculate three sets of data on $\mathrm{Ni}$ and $\mathrm{NiH}$ :

- the molar volume as a function of the temperature (Figure 4) 
- the thermal expansion coefficient defined as $\alpha=\frac{1}{3} \frac{1}{V_{m}}\left(\frac{\partial V_{m}}{\partial T}\right)_{P, n_{i}}$ directly determined from the first derivative of the first data set

- the bulk modulus $B=-V\left(\frac{\partial P}{\partial V}\right)_{T, n_{i}}$.

The calculated thermal properties for pure $\mathrm{Ni}$ are in excellent agreement with the experimental studies (Figure 4) and were used to assess the parameters of the model of Lu et al. for both $\mathrm{Ni}$ and $\mathrm{NiH}$.

From the QHA-phonon calculations, the NiH structure has been found intrinsically unstable at temperatures above $600 \mathrm{~K}$.

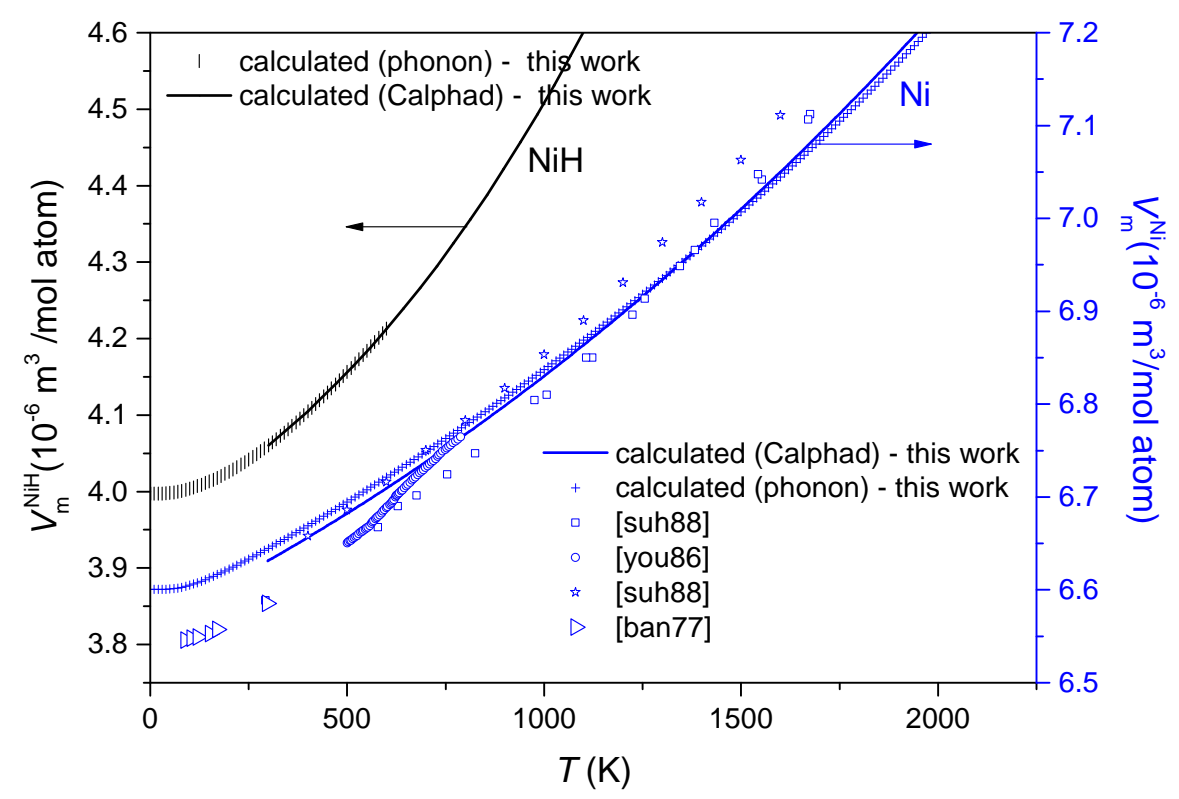

Figure 4: Molar volumes of $\mathrm{Ni}$ (blue, right-hand scale) and $\mathrm{NiH}$ (black, left-hand scale) as a function of temperature determined by phonon calculations and Calphad modeling (this work). Experimental data from Suh et al., ${ }^{16}$ Yousuf et al., ${ }^{16}$ Von Batchelder and Raeuchle ${ }^{18}$ and Bandyopadhyay and Gupta. ${ }^{19}$

\subsection{Calphad results}

The system has been modeled using the Parrot module ${ }^{84}$ of Thermo-Calc. ${ }^{85}$ One may find the corresponding thermodynamic database (TDB file format) in supporting information. 
First, the four parameters $V_{0}, V_{A}, V_{C}$ and $V_{K}$ of the high pressure model were determined for each end members of the condensed phases independently. The volume temperature and pressure dependence parameters of the solid end members $\mathrm{Ni}$ and $\mathrm{NiH}$ were optimized with the same procedure, using only DFT and quasi-harmonic phonon data (Sections 5.1 and 5.3). These calculated data were essential for $\mathrm{NiH}$, as no experimental data was available in the literature.

The high pressure parameters of liquid nickel were optimized by the exclusive use of experimental data. As short range order in liquids is optimally fitted by a bcc configuration, the molar volume of reference $V_{0}$ of the liquid end member $\mathrm{NiH}$ was estimated equal to the solid NiH molar volume, multiplied by the bcc/fcc compressibilities ratio. It is generally admitted that the structure of the liquid resembles the configuration of the bcc phase. Therefore, we assume that the ratio $V_{0, \mathrm{Ni}: \mathrm{H}}^{\mathrm{liq}} / V_{0, \mathrm{Ni}: \mathrm{H}}^{\mathrm{fcc}}$ equals the compacity ratio between bcc and fcc phases 0.920. $V_{A}, V_{C}$ and $V_{K}$ were set at the same values as for pure liquid nickel, assuming that the thermal and pressure behaviors are not significantly affected by hydrogen solubility. Attention was paid to keep the parameters and their corresponding physical quantities to relevant values, on the complete set of temperatures and pressures.

After optimization, a satisfactory agreement with the available experimental and theoretical data could be reached as shown in Figures 4,5 and 6 for pure nickel. The calculated coefficient of isothermal compressibility of $5.2 \times 10^{-12} \mathrm{~Pa}^{-1}$ agrees properly with the experimental one $\left(5.4 \times 10^{-12} \mathrm{~Pa}^{-1}\right)$. 


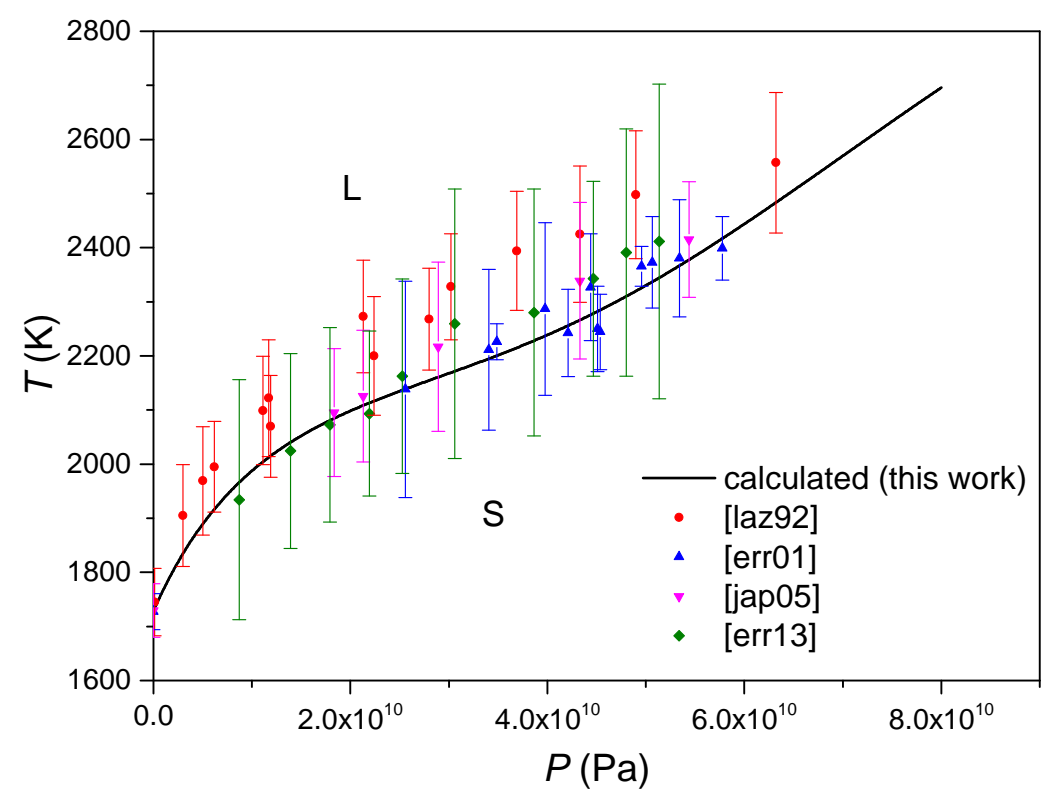

Figure 5: Calculated P-T phase diagram of pure Ni. Experimental data from Lazor et al., ${ }^{36}$ Errandonea et al., ${ }^{37}$ Japel et al. ${ }^{38}$ and Errandonea. ${ }^{39}$

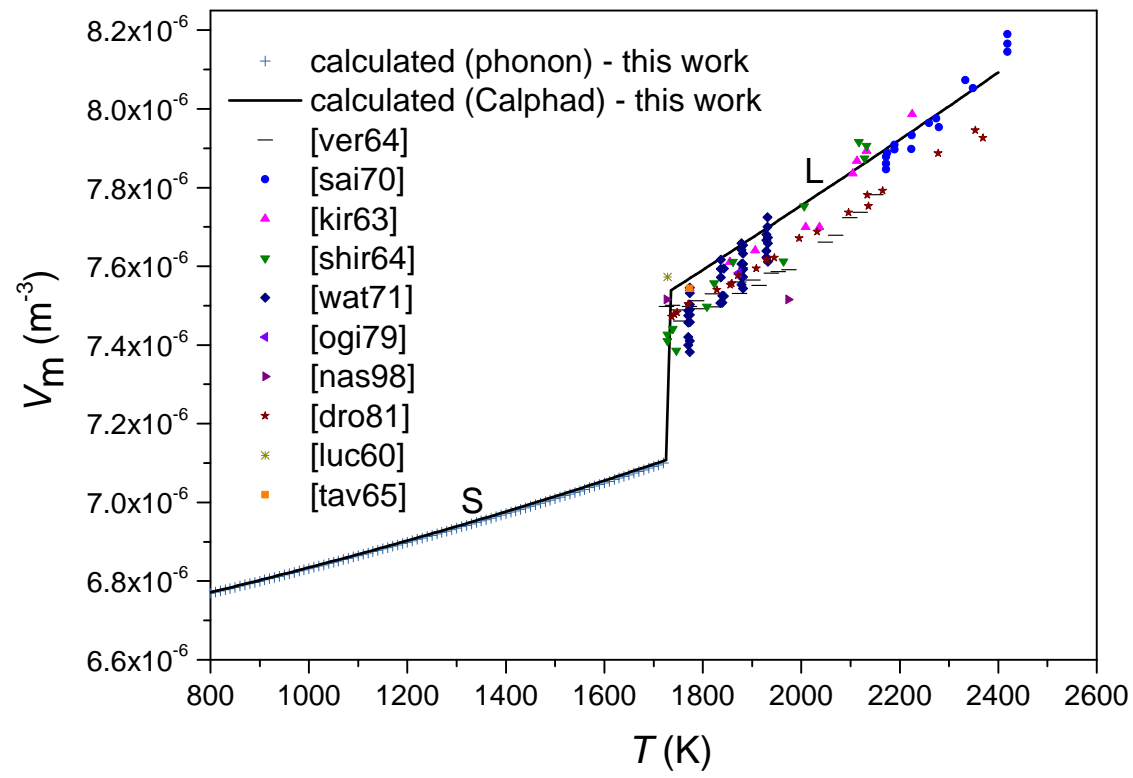

Figure 6: Calculated Ni molar volume increase at the melting point. Experimental data from Vertman et al.,${ }^{24}$ Tavadze, ${ }^{33}$ Saito and Sakuma, ${ }^{25}$ Kirschenbaum and Cahill, ${ }^{26}$ Shiraishi and Ward, ${ }^{27}$ Watanabe et al. ${ }^{28}$ Ogino et al. ${ }^{29}$ Nasch and Manghnani ${ }^{30}$ and Drotning. ${ }^{31}$ 
The high pressure model for the liquid phase allows to minimize the gas relative destabilization in the high pressure range. The boiling point variations with pressures are thus more reasonable in the conditions where hydrogen is in its gaseous state (Figure 7).

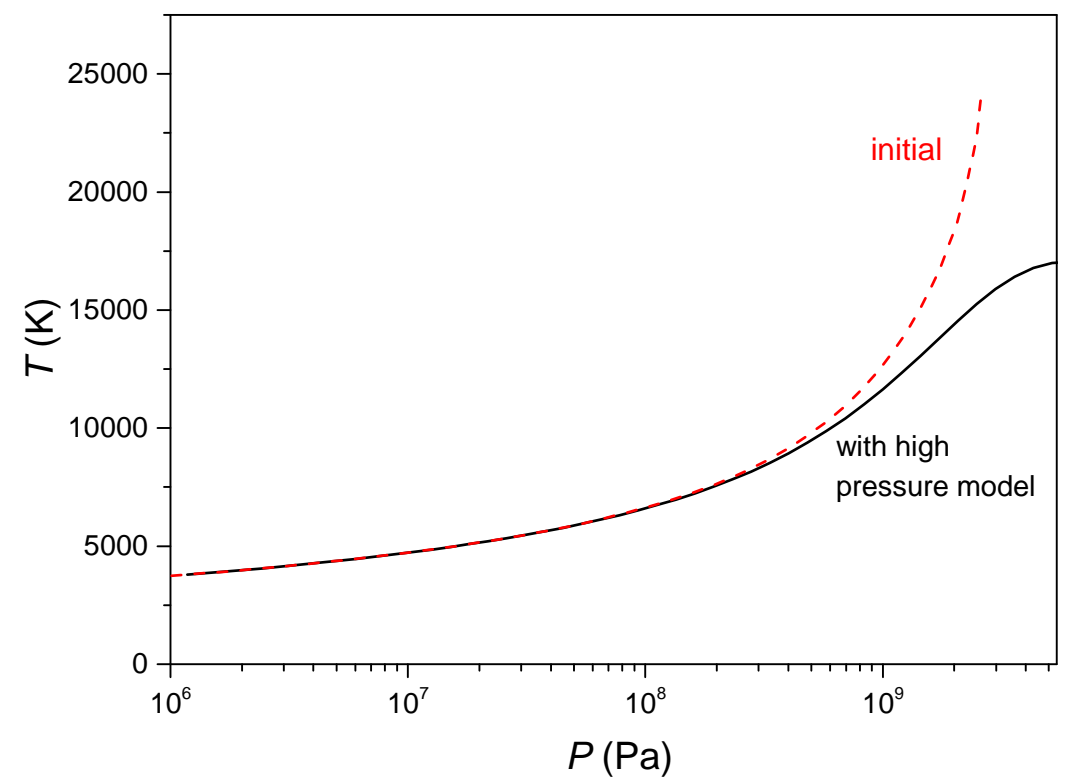

Figure 7: Calculated $P-T$ phase diagram of pure $\mathrm{Ni}$ with (dark solid line) and without (red dashed line) specific high pressure model for condensed phases).

Finally, the complete set of parameters for the system $\mathrm{Ni}-\mathrm{H}$ was assessed. The starting values for $G_{\mathrm{Ni}: \mathrm{H}}^{\varphi}(\varphi=\mathrm{fcc}, \mathrm{LIQ})$ and $L_{\mathrm{H}: \mathrm{VA}}^{0, \mathrm{LI}}$ were evaluated in agreement with Zeng's model. $L_{\mathrm{H}, \mathrm{VA}}^{0, \text { fcc }}$ was defined as a function of temperature. The asymmetry of the miscibility gap was described using a temperature constant irregular interaction term. The entire set of parameters in the fcc phase were assessed considering the selected experimental and calculated data. To describe properly the curvature of the experimentally measured $\mathrm{H}$ solubility at $10^{5}$ and $10^{7} \mathrm{~Pa}$, it has been found necessary to add a $T^{2}$ term to describe $G_{\mathrm{Ni}: \mathrm{H}}^{\varphi}$, corresponding to the slope of the heat capacity as a function of temperature. This parameter was thus refined in accordance with the trend of the calculated heat capacity curve. As little information was available on the liquid phase, only a constant regular interaction parameter was considered. It represents the interaction between hydrogen and vacancies (VA) on the second sublattice, 
identically to the fcc phase.

$$
L_{\mathrm{H}: \mathrm{VA}}^{0, \mathrm{LIQ}}=a^{0, \mathrm{LIQ}}
$$

The three parameters of the liquid phase $V_{4}, V_{5}$ and $a^{0, \mathrm{LIQ}}$ were refined on the basis of the 3 -phase equilibrium data ${ }^{41,70}$ and the solubility data of Sieverts. ${ }^{40}$ Finally, all parameters were optimized simultaneously with all the selected experimental and theoretical data. Their final values are summarized in Table 2 .

The model could reproduce satisfactorily the available isobaric and isotherm solubility measurements in the whole pressure range from very low (1 to $240 \mathrm{~Pa}$ ) (Figure 8 ) to moderate pressures $\left(10^{5}\right.$ and $\left.10^{7} \mathrm{~Pa}\right)$ (Figure 9$)$. It can be noted that the present model underestimates the solubility measurements of Smittenberg. ${ }^{47}$ This discrepancy was already pointed out by Zeng and explained by experimental inaccuracies on the pressure, which value may be slightly higher than $13.3 \mathrm{~Pa}$. Indeed, our calculated curve around $17.5 \mathrm{~Pa}$ is nearly superimposed to the experimental points. This assumption is confirmed by comparing the isothermal measurements of the same author with the ones of Armbruster. ${ }^{54}$ 


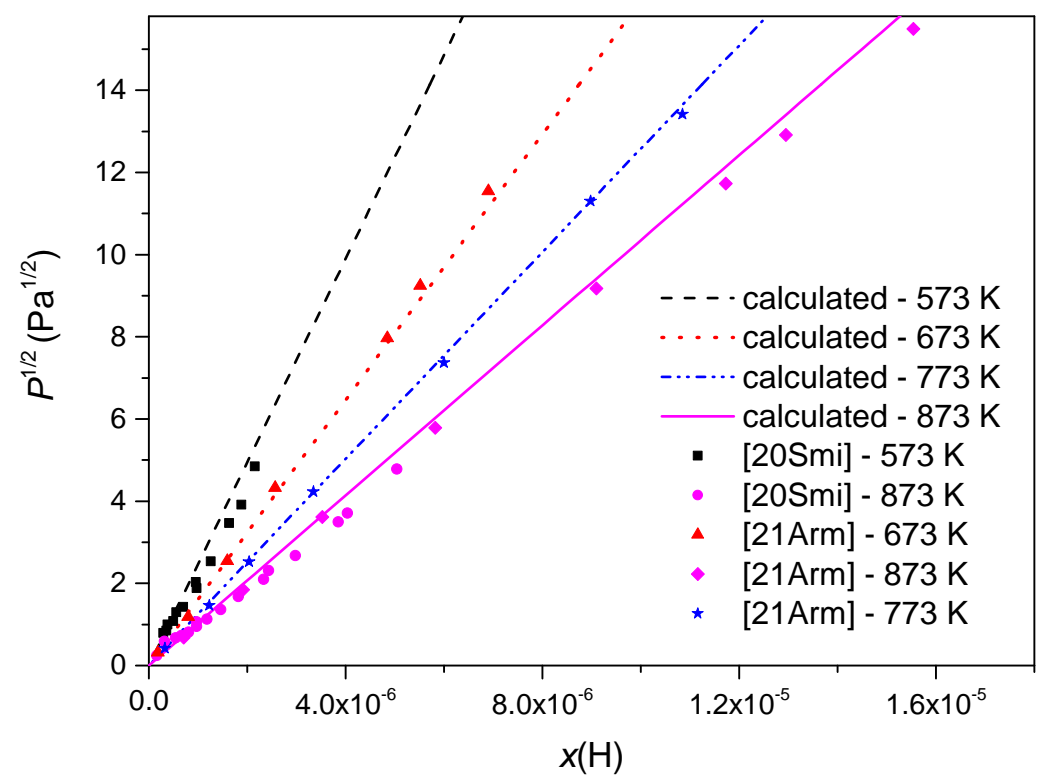

Figure 8: Calculated hydrogen solubility in Ni at low pressure and constant temperatures. Experimental solubility measurements of Smittenberg ${ }^{47}$ and Armbruster ${ }^{54}$ at constant temperature. 


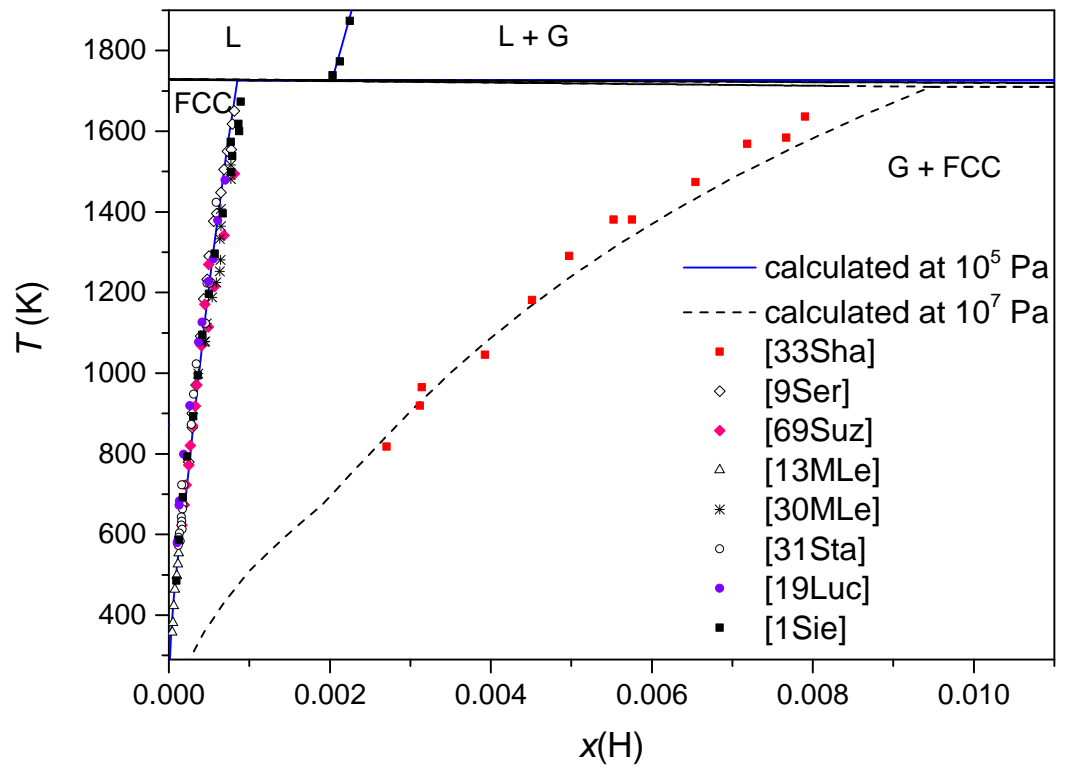

Figure 9: Calculated $\mathrm{Ni}-\mathrm{H}$ phase diagrams at moderate pressure: $1.0 \times 10^{5} \mathrm{~Pa}$ (blue solid line) and $1.0 \times 10^{7} \mathrm{~Pa}$ (black dashed line). Experimental isobaric measurements of Sieverts, ${ }^{40}$ Shapovalov and Serdyuk, ${ }^{41}$ Serdyuk and Chuprina, ${ }^{42}$ Suzuki and McLellan, ${ }^{43}$ Mc Lellan and Sutter, ${ }^{44}$ McLellan and Oates, ${ }^{74}$ Stafford and McLellan ${ }^{45}$ and Luckemeyer-Hasse and Schenck. ${ }^{46}$

Besides, a difficult point was the description of the solid-liquid-gas equilibrium temperature as a function of pressure measured by Shapovalov and Serdyuk, ${ }^{41}$ particularly in the region between $2 \times 10^{7}$ and $4 \times 10^{7} \mathrm{~Pa}$ where the model overestimates the equilibrium temperature (Figure 10). Probably related with the simple model used for the liquid phase, the discrepancy reduces however at higher pressures. 


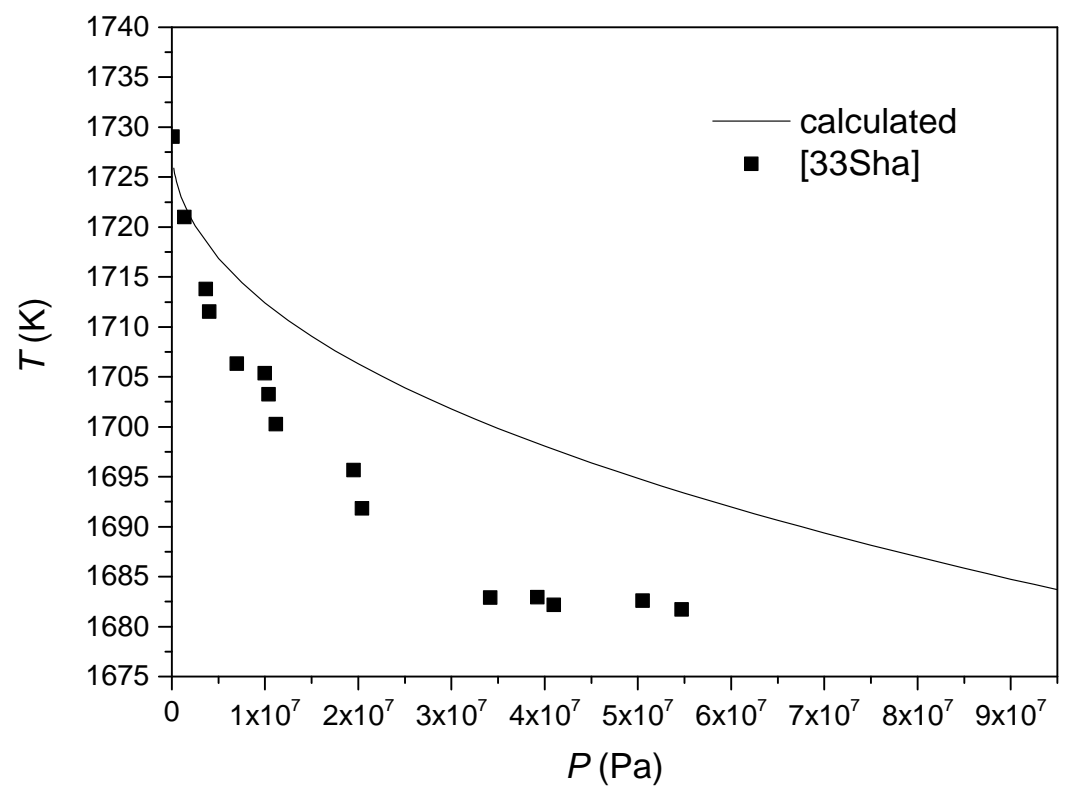

Figure 10: Solid-liquid-gas equilibrium temperature as a function of pressure compared with the data of Shapovalov and Serdyuk. ${ }^{41}$

At low hydrogen content, the solution of hydrogen in nickel is known to be an endothermic process. While increasing hydrogen content, the reaction heat decreases from positive to negative values. This transition from an endothermic to an exothermic reaction of $\mathrm{Ni}$ with $\mathrm{H}$ was theoretically predicted, ${ }^{86-88}$ notably by the mean-field lattice gas model of Driessen et al. and corroborated by the calorimetric measurements of Czarnota and Baranowski. ${ }^{72}$ The present model predicts also this characteristic feature of the $\mathrm{Ni}-\mathrm{H}$ system, highlighted in Figure 11 where several calculated pressure-composition isotherms at different temperatures are represented: for low $\mathrm{H}$ content, the reaction is endothermic and a temperature increase yields a lower equilibrium pressure for a given $\mathrm{H}$ concentration. Conversely, for higher $\mathrm{H}$ content, the reaction is exothermic and an increasing temperature increases the equilibrium pressure. A crossing of the isotherm was therefore anticipated and is here shown for the first time in a Calphad model. 


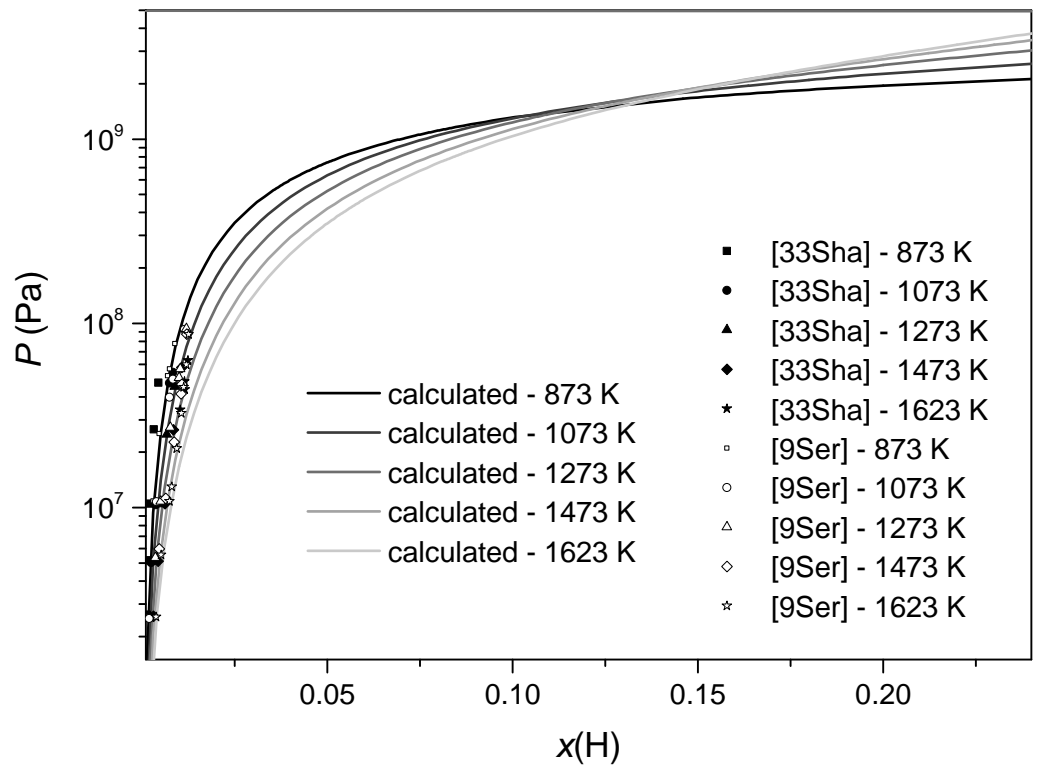

Figure 11: Pressure-composition isotherms at different temperatures from 873 to $1623 \mathrm{~K}$. The crossing is characteristic of the transition from an endo to exothermic reaction as a function of hydrogen concentration. Experimental solubility measurements of Shapovalov and Serdyuk ${ }^{41}$ and Serdyuk and Chuprina ${ }^{42}$ at constant temperature.

The plateau pressure was assessed following the curve measured during $\mathrm{NiH}$ decomposition $^{69}$ as shown in Figures 12 and 13. 


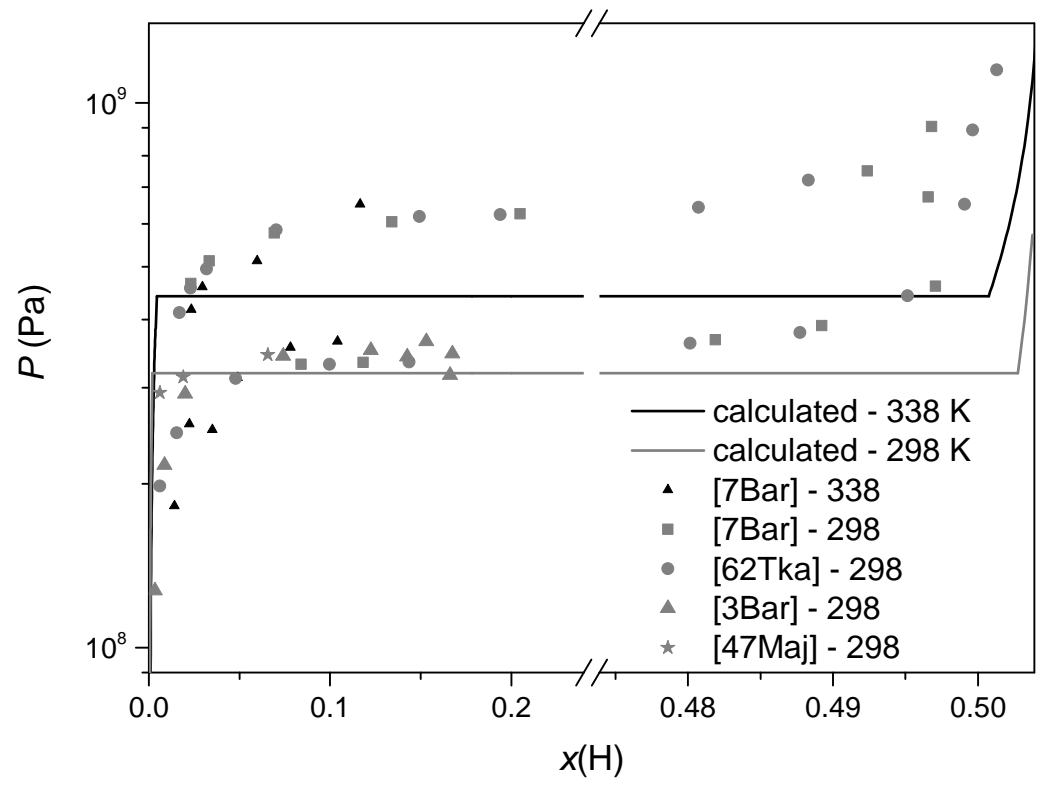

Figure 12: Pressure-composition isotherms at 298 and $338 \mathrm{~K}$. Experimental measurements of Baranowski, ${ }^{63,64}$ Tkacz $^{65}$ and Majchrzak. ${ }^{62}$ 


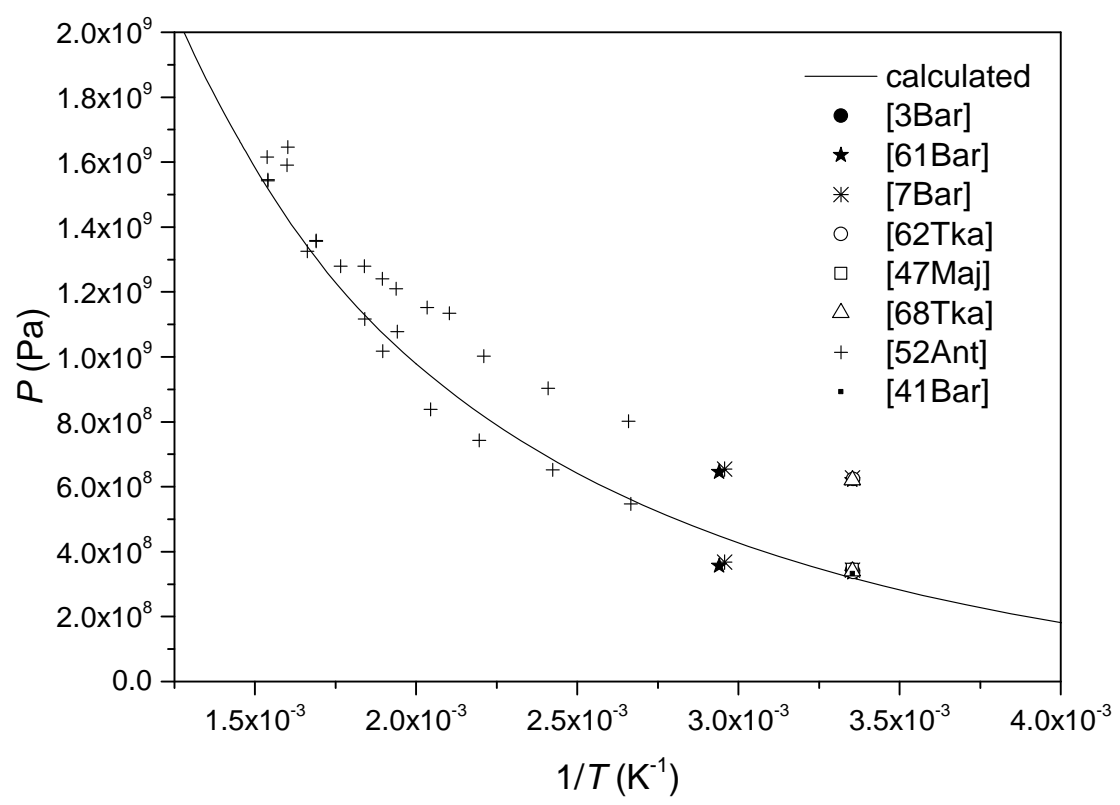

Figure 13: Calculated plateau pressure in the $\mathrm{Ni}-\mathrm{H}$ system as a function of the inverse temperature from $298 \mathrm{~K}$ to $651 \mathrm{~K}$. Experimental plateau pressure of Baranowski and Czarnota, ${ }^{63}$ Baranowski and Tkacz,${ }^{66}$ Baranowski, ${ }^{64}$ Tkacz, ${ }^{65}$ Majchrzak, ${ }^{62}$ Tkacz and Baranowski, ${ }^{67}$ Antonov et al., ${ }^{69}$ Baranowski and Bochenska. ${ }^{68}$

At high pressure, the model highlights the formation of a large miscibility gap (Figure 14). The scarce available experimental data on the solubility branches ${ }^{56,69}$ are correctly reproduced. 


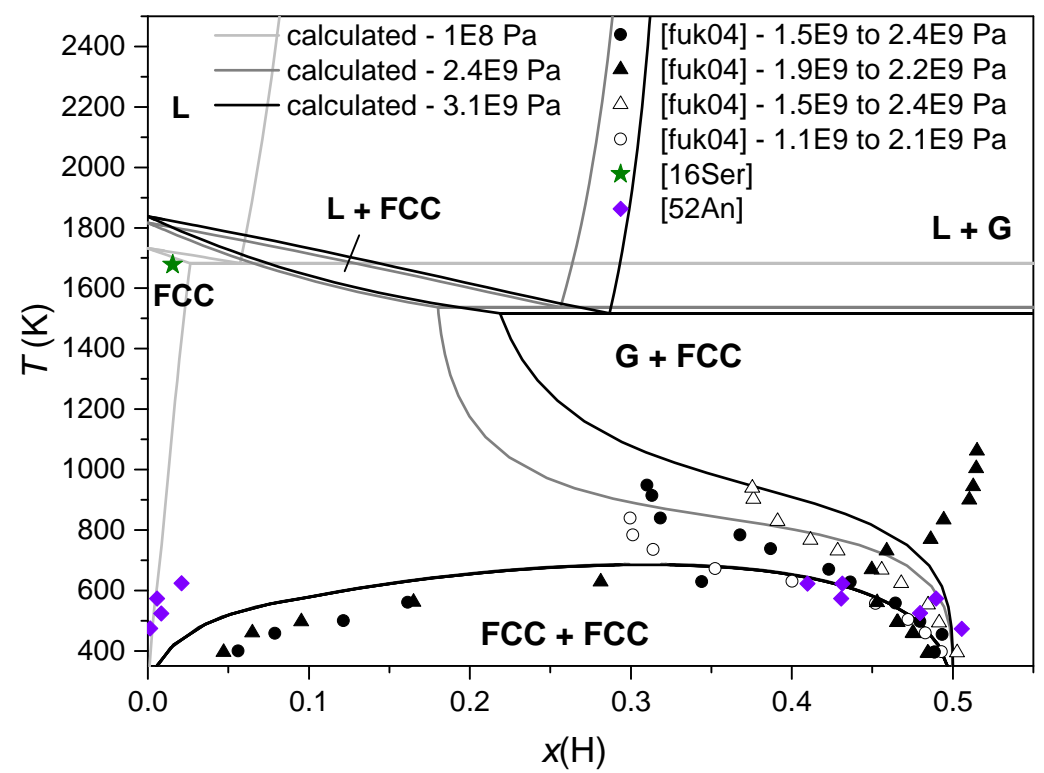

Figure 14: $\mathrm{Ni}-\mathrm{H}$ phase diagrams at several pressures highlighting the miscibility gap formation. Experimental solubility branches of the miscibility gap of Antonov et al. ${ }^{69}$ and Fukai et al. ${ }^{56}$ solubility data in the hydrogen rich fcc phase ${ }^{56}$ measured on a hydrogenated sample during cooling (empty symbols) or heating (filled symbols) and 3-phase equilibrium of Serdyuk et al. ${ }^{70}$ 
Table 2: Results of the assessment.

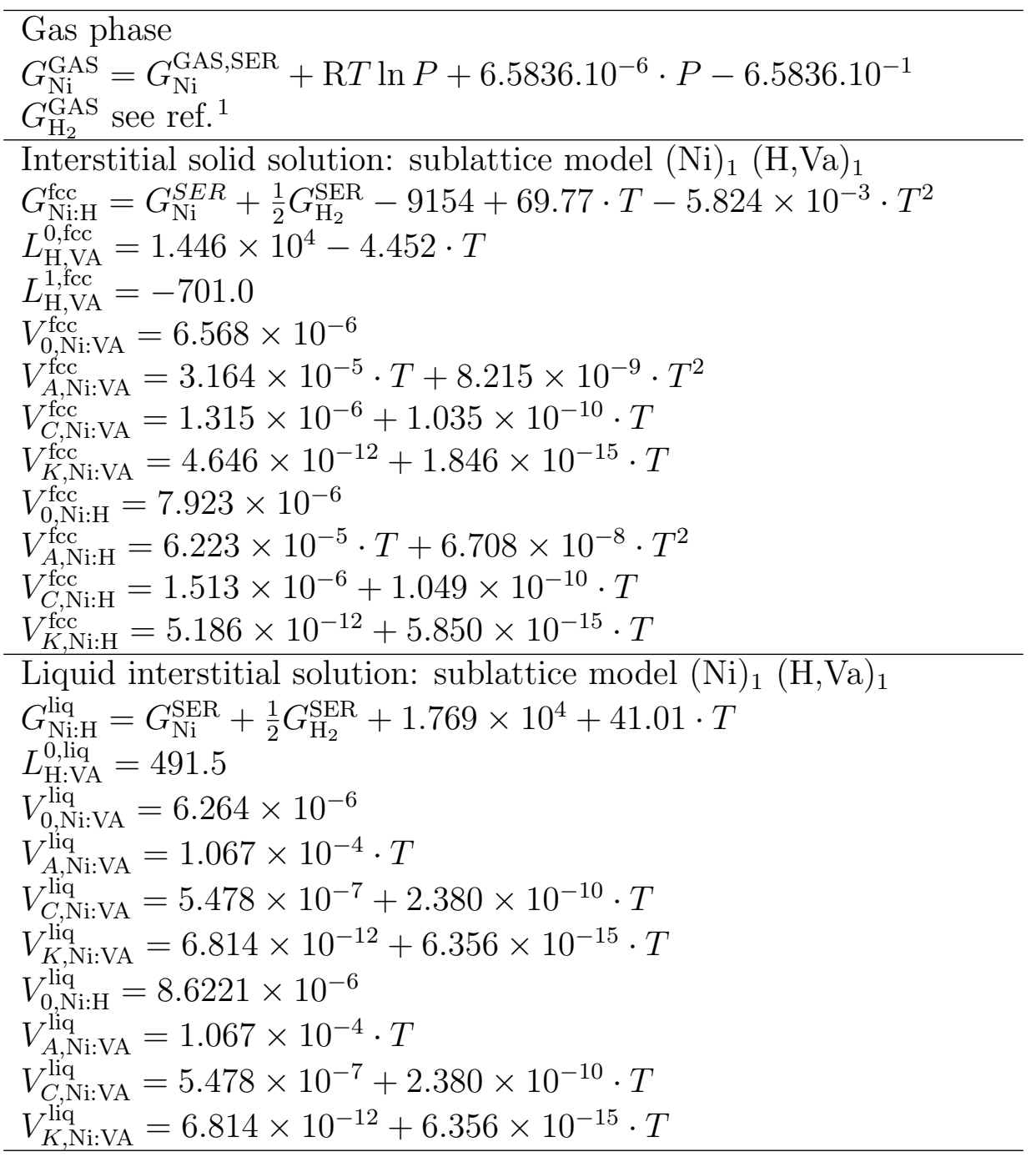

\section{Conclusion}

The present Calphad optimization provides a new description of the $\mathrm{Ni}-\mathrm{H}$ system including the NiH hydride formation at high pressures and the miscibility gap. Coupled with QHAphonon calculations, the DFT contributed to offset the scarceness of available experimental data on $\mathrm{NiH}$.

The CEM method provided essential information to describe the fcc solid solution in the Calphad model. It appeared as a very useful method to determine enthalpies of mixing in a 
metastable solid solution which were used in the present model to improve the description of the excess Gibbs energy in the present Calphad model.

Two phenomenological models were effectively used to take into account the pressure effect on solid, liquid and gaseous phases. First, the model of Joubert ${ }^{78}$ allowed to consider the non ideality of gaseous hydrogen. Second, the model of Lu et al. ${ }^{5}$ was applied to both liquid and solid phases, improving the reliability of high pressure extrapolations. In this frame, the available experimental data could be satisfactorily reproduced over the entire pressure range. Besides, the new sublattice model adopted for the liquid phase makes the system compatible if one wants to built a database with other $M-\mathrm{H}$ systems and facilitates the development of a future database centered on hydrogen.

\section{Acknowledgement}

This work has benefited from a French government grant managed by ANR within the frame of the national program Investments for the Future ANR-11-LABX-022-01. DFT calculations were performed using HPC resources from GENCI-CINES (Grant 2014-96175).

\section{References}

(1) Joubert, J. M. JOM 2012, 64(12), 1438-1447.

(2) Zeng, K.; Klassen, T.; Oelerich, W.; Bormann, R. J. Alloys Compd. 1999, 283, 151-161.

(3) Kohn, W.; Sham, L. Phys. Rev. 1965, 140, 1133-1138.

(4) Sanchez, J. M.; Ducastelle, F.; Gratias, D. Phys. A (Amsterdam, Neth.) 1984, 128, $334-350$.

(5) Lu, X.-G.; Selleby, M.; Sundman, B. Calphad 2005, 29, 49-55.

(6) Kresse, G.; Furthmüller, J. Phys. Rev. B 1996, 54, 11169. 
(7) Kresse, G.; Joubert, D. Phys. Rev. B 1999, 59, 1758.

(8) Perdew, J. P.; Ernzerhof, M.; Burke, K. J. Chem. Phys. 1996, 105, 9982-9985.

(9) Perdew, J.; Burke, K.; Ernzerhof, M. Errata:(1997) Phys Rev Lett 1996, 78, 1396.

(10) Monkhorst, H. J.; Pack, J. D. Phys. Rev. B 1976, 13, 5188.

(11) Togo, A.; Oba, F.; Tanaka, I. Phys. Rev. B 2008, 78, 134106.

(12) van de Walle, A.; Ceder, G. J. Phase Equilib. 2002, 23, 348-359.

(13) Connolly, J.; Williams, A. Phys. Rev. B 1983, 27, 5169.

(14) Ågren, J.; Brechet, Y.; Hutchinson, C.; Philibert, J.; Purdy, G. Thermodynamics and Phase Transformations: the Selected Works of Mats Hillert; EDP Sciences, 2006.

(15) Lukas, H. L.; Fries, S. G.; Sundman, B. Computational Thermodynamics: the Calphad Method; Cambridge university press Cambridge, 2007; Vol. 131.

(16) Suh, I.-K.; Ohta, H.; Waseda, Y. J. Mater. Sci. 1988, 23, 757-760.

(17) Yousuf, M.; Sahu, P. C.; Jajoo, H. K.; Rajagopalan, S.; Rajan, K. G. J. Phys. F: Met. Phys. 1986, 16, 373.

(18) Von Batchelder, F. W.; Raeuchle, R. F. Acta Crystallogr. 1954, 7, 464.

(19) Bandyopadhyay, J.; Gupta, K. P. Cryogenics 1977, 17, 345-347.

(20) Touloukian, Y. S.; Kirby, R. K.; Taylor, R. E.; Desai, P. D. Thermophysical Properties of Matter-the TPRC Data Series. Volume 12. Thermal Expansion Metallic Elements and Alloys.; 1975.

(21) Ho, C. Y. Properties of Selected Ferrous Alloying Elements; Hemisphere New York, 1989. 
(22) Zhang, J.; Zhao, Y.; Palosz, B. Appl. Phys. Lett. 2007, 90, 43112.

(23) Schramm, K. H. Z. Metallkd. 1962, 53, 316-320.

(24) Vertman, A. A.; Filippov, E. S.; Samarin, A. M. Dokl. Akad. Nauk 1964, 155, 323.

(25) Saito, T.; Sakuma, Y. Sci. Rep. Res. Inst. Tohoku Univ 1970, 22A, 57-65.

(26) Kirschenbaum, A.; Cahill, J. Trans. Am. Soc. Met. 1961, 2, 281.

(27) Shiraishi, S. Y.; Ward, R. G. Can. Metall. Q. 1964, 3, 117-122.

(28) Watanabe, S.; Amatatu, M.; Saito, T. Densities of Fe-Ni, Co-Ni, Co-Mo, and Co-W Alloys in Liquid State.; 1971.

(29) Ogino, K.; Taimatsu, H. J. Jpn. Inst. Met. 1979, 43, 871-876.

(30) Nasch, P. M.; Manghnani, M. H. Properties of Earth and Planetary Materials at High Pressure and Temperature 1998, 307-317.

(31) Drotning, W. D. High Temp. - High Pressures 1981, 13, 441-458.

(32) Lucas, L. D. C. R. Hebd. Seances Acad. Sci. 1960, 250, 1850-1852.

(33) Tavadze, F. N.; Bairamas, I.; Khantadz, D. Dokl. Akad. Nauk 1965, 162, 67-\&.

(34) Kozakevitch, P.; Urbain, G. C. R. Hebd. Seances Acad. Sci. 1961, 253, 2229.

(35) Eljutin, V. P.; Kostikov, V. I. Poroshk. Met 1970, 9, 45-46.

(36) Lazor, P.; Shen, G.; Saxena, S. K. Phys. Chem. Miner 1993, 20, 86-90.

(37) Errandonea, D.; Schwager, B.; Ditz, R.; Gessmann, C.; Boehler, R.; Ross, M. Phys. Rev. B 2001, 63, 132104 .

(38) Japel, S.; Schwager, B.; Boehler, R.; Ross, M. Phys. Rev. Lett. 2005, 95, 167801. 
(39) Errandonea, D. Phys. Rev. B 2013, 87, 54108.

(40) Sieverts, A. Z. Metallkd. 1929, 21, 37-46.

(41) Shapovalov, V. I.; Serdyuk, N. P. Russ. J. Phys. Chem. 1979, 53, 1250-1252.

(42) Serdyuk, N.; Chuprina, A. Russ. J. Phys. Chem. 1980, 11, 1615-1618.

(43) Suzuki, Y.; Mc Lellan, R. Acta Metall. 1986, 34(1), 125-130.

(44) Mc Lellan, R.; Sutter, P. Acta Metall. 1984, 32(12), 2233-2239.

(45) Stafford, S. W.; Mc Lellan, R. B. Acta Metall. 1974, 22(12), 1463-1468.

(46) Luckemeyer-Hasse, L.; Schenck, H. Löslichkeit von Wasserstoff in einigen Metallen und Legierungen; Verlag Stahleisen, 1932.

(47) Smittenberg, J. Recl. Trav. Chim. Pays-Bas 1934, 53(12), 1065-1083.

(48) Jones, F.; Pehlke, R. Metall. Trans. 1971, 2, 2655-2663.

(49) Eichenauer, W.; Löser, W.; Witte, H. Z. Metallkd. 1965, 56, 287.

(50) Lee, S.-M.; Lee, J.-Y. Metall. Trans. A 1986, 17, 181-187.

(51) Combette, P.; Azou, P. Mem. Etud. Sci. Rev. Metall. 1970, 67, 17-33.

(52) Blakemore, J.; Oates, W.; Hall, E. Trans. Metall. Soc. AIME 1968, 242.

(53) Lieser, K.; Rinck, G. Z. Elektrochem. 1957, 61, 357-359.

(54) Armbruster, M. H. J. Am. Chem. Soc. 1943, 65(6), 1043-1054.

(55) Vyatkin, A. F.; Zhorin, P. V.; Tseitlin, E. M. Russ. J. Phys. Chem. 1983, 57(2), $419-422$.

(56) Fukai, Y.; Yamatomo, S.; Harada, S.; Kanazawa, M. J. Alloys Compd. 2004, 372, L4-L5. 
(57) Shizuku, Y.; Yamamoto, S.; Fukai, Y. J. Alloys Compd. 2002, 336, 159-162.

(58) Baranowski, B. Bull. Acad. Pol. Sci., Chim. 1959, 7, 897-905.

(59) Bauer, H.; Berninger, G.; Zimmerman, G. Z. Naturforsch., A: Phys. Sci. 1968, 23, 2023-2029.

(60) Szklarska-Smialowska, Z.; Smialowski, M. J. Electrochem. Soc. 1963, 110, 444-448.

(61) Wayman, M.; Smith, G. J. Phys. Chem. Solids 1971, 32, 103-108.

(62) Majchrzak, S. Bull. Acad. Pol. Sci., Ser. Sci. Chim. 1967, 15, 485-490.

(63) Baranowski, B. Ber. Bunsen Ges. Phys. Chem. 1972, 76, 714-724.

(64) Baranowski, B. Hydrogen in Metals II, Springer-Verlag Berlin 1978, 29, 157-200.

(65) Tkacz, M. J. Chem. Thermodyn. 2001, 33(8), 891-897.

(66) Baranowski, B.; Tkacz, M. Pol. J. Chem. 1980, 54(4), 819-825.

(67) Tkacz, M.; Baranowski, B. J. Less-Common Met. 1985, 113(1), 83-87.

(68) Baranowski, B.; Bochenska, K. Z. Phys. Chem. (Muenchen, Ger.) 1965, 45, 140-152.

(69) Antonov, V. E.; Belash, I. T.; Poniatovskii, E. G. Dokl. Akad. Nauk 1977, 233(6), $1114-1117$.

(70) Serdyuk, N. P.; Trofimenko, V. V.; Dukelskii, Y. M. Russ. Metall. 1992, 5, 201-204.

(71) Baranowski, B.; Czarnota, I. Naturwissenschaften 1964, 51, 262.

(72) Czarnota, I.; Baranowski, B. Bull. Acad. Pol. Sci., Ser. Sci. Chim. 1966, 14.

(73) Lucas, L. D. Mém. Scient. Rev. Métallurg. 1964, 61, 1-24.

(74) Mc Lellan, R.; Oates, W. Acta Metall. 1973, 34(1), 125-130. 
(75) Baranowski, B.; Kochenska, K.; Majchrzak, S. Pol. J. Chem. 1967, 41, 2071-2082.

(76) Dinsdale, A. Calphad 1991, 15, 317-425.

(77) Ansara, I.; Sundman, B. Computer Handling and Dissemination of Data 1987, 154158.

(78) Joubert, J.-M. Int. J. Hydrogen Energy 2012, 35(5), 2104-2111.

(79) Hillert, M.; Staffansson, L. Acta Chem. Scand. 1970, 24, 3618-3626.

(80) Redlich, O.; Kister, A. Ind. Eng. Chem. 1948, 40, 345-348.

(81) Inden, G. Project Meeting Calphad V; Max-Planck Institut for Eisenforschung, Düsseldorf, Germany, 1976; pp 21-25.

(82) Hillert, M.; Jarl, M. Calphad 1978, 2, 227-238.

(83) Grover, R.; Getting, I.; Kennedy, G. Phys. Rev. B 1973, 7, 567.

(84) Sundman, B.; Jansson, B.; Andersson, J.-O. Calphad 1985, 9, 153-190.

(85) Andersson, J.-O.; Helander, T.; Höglund, L.; Shi, P.; Sundman, B. Calphad 2002, 26, 273-312.

(86) Yurichev, I.; Ponyatovskii, E. Phys. Status Solidi A 1980, 58, 57-66.

(87) Fukai, Y.; Sugimoto, H. Trans. Jpn. Inst. Met. 1983, 733-740.

(88) Driessen, A.; Sanger, P.; Hemmes, H.; Griessen, R. J. Phys.: Condens. Matter 1990, 2, 9797. 